J. Am. Chem. Soc.

revised

\title{
Ionization Thresholds of Small Carbon Clusters: Tunable VUV Experiments and Theory
}

Leonid Belau, ${ }^{1}$ Steven E. Wheeler, ${ }^{2}$ Brian W. Ticknor, ${ }^{2}$ Musahid Ahmed, ${ }^{1}$ Stephen R. Leone, ${ }^{1,3}$ Wesley D. Allen, ${ }^{2}$ Henry F. Schaefer III, ${ }^{2}$ and Michael A. Duncan ${ }^{2} *$

${ }^{1}$ Chemical Sciences Division, Lawrence Berkeley National Laboratory, 1 Cyclotron Road, Berkeley, CA 94720

${ }^{2}$ Department of Chemistry, University of Georgia, Athens, GA 30602

${ }^{3}$ Department of Chemistry and Physics, University of California, Berkeley, CA 94720

*Corresponding author: maduncan@uga.edu

\section{Abstract}

Small carbon clusters $\left(C_{n}, n=2-15\right)$ are produced in a molecular beam by pulsed laser vaporization and studied with vacuum ultraviolet (VUV) photoionization mass spectrometry. The required VUV radiation in the $8-12 \mathrm{eV}$ range is provided by the Advanced Light Source (ALS) at the Lawrence Berkeley National Laboratory. Mass spectra at various ionization energies reveal the qualitative relative abundances of the neutral carbon clusters produced. By far the most abundant species is $\mathrm{C}_{3}$. Using the tunability of the ALS, ionization threshold spectra are recorded for the clusters up to 15 atoms in size. The ionization thresholds are compared to those measured previously with charge transfer bracketing methods. To interpret the ionization thresholds for different cluster sizes, new ab initio calculations are carried out on the clusters for $\mathrm{n}=4-10$. Geometric structures are optimized at the $\operatorname{CCSD}(\mathrm{T})$ level with cc-pVTZ (or cc-pVDZ) basis sets, and focal point extrapolations are applied to both neutral and cation species to 
determine adiabatic and vertical ionization potentials. The comparison of computed and measured ionization potentials makes it possible to investigate the isomeric structures of the neutral clusters produced in this experiment. The measurements are inconclusive for the $n=4-6$ species because of unquenched excited electronic states. However, the data provide evidence for the prominence of linear structures for the $n=7,9,11,13$ species and the presence of cyclic $C_{10}$.

\section{Introduction}

From $\mathrm{C}_{2}$ and $\mathrm{C}_{3}$ to the fullerenes, carbon atom clusters provide fascinating examples of molecular structure and bonding. ${ }^{1-11}$ As cluster size increases, linear chains, cyclic structures and three dimensional cages are produced. Small carbon clusters are important in astrophysics ${ }^{9-12}$ and combustion, ${ }^{13}$ while larger species such as the fullerenes and carbon nanotubes are of growing importance for new materials. ${ }^{3,4}$ Therefore the study of the molecular structure and bonding in these systems continues to fascinate and challenge both experiment and theory. Although there have been extensive studies on these systems, many questions remain unanswered. The composition of small neutral species present in the gas phase is critical to the mechanism of fullerene and nanotube growth, ${ }^{14,15}$ yet it is notoriously difficult to measure neutral concentrations without some bias from ionization and fragmentation processes in mass spectrometers. Likewise, the dominant structures present in the small clusters (linear versus cyclic) are difficult to predict with theory, but these structures are the building blocks for larger materials. In the present work, we approach these issues in a new way with vacuum ultraviolet (VUV) photoionization mass spectrometry. Tunable VUV from the Advanced Light Source (ALS) is employed to investigate ionization thresholds, ionization cross sections and the relative abundances of neutral carbon clusters present in a laser vaporization plasma. In coordination with new high-level theoretical computations, the ionization thresholds allow us to identify the structures of the small clusters present in this environment.

Carbon clusters in the small size range have been described in many mass spectrometry

experiments. ${ }^{16-23}$ Depending on the details of the experiment and the ionization method employed, certain cluster ions stand out as more prominent, and these have been speculated to be 
more stable based on their enhanced abundances. Of course the most famous example of this occurs in the larger cluster sizes for $\mathrm{C}_{60}$ and the higher fullerenes. ${ }^{2-4,17}$ Unfortunately, it is now understood that many of the earlier results on smaller clusters were misleading because of the variation of the ionization potential with cluster size and fragmentation in the ionization processes employed. To circumvent some of these difficulties, other experiments have sampled ionized cation or anion clusters directly ${ }^{18}$ and have investigated mass-selected photodissociation, ${ }^{23-27}$ metastable ion decay ${ }^{28,29}$ and collision induced dissociation ${ }^{25,30}$ of these ions. It was found that cations in the small size range usually eliminate $\mathrm{C}_{3}$ when they dissociate, while larger clusters in the fullerene family eliminate $\mathrm{C}_{2}$. However, it has been particularly difficult to characterize the neutral carbon cluster distribution. Ionization potentials of carbon clusters have been bracketed with charge exchange experiments, ${ }^{31}$ which find values for the clusters smaller than 10 atoms in the range of $9-13 \mathrm{eV}$. This energy range is greater than that available from convenient ultraviolet laser sources, and therefore photoionization experiments have most often involved multiphoton processes, resulting in fragmentation. Recently, vacuum ultraviolet photoionization experiments have been described at the $118 \mathrm{~nm}$ wavelength $(10.5 \mathrm{eV})$ available from Nd:YAG laser ninth harmonic generation. ${ }^{32,33}$ However, even this photon energy is not great enough for single photon ionization of all the small carbon clusters, and so an unbiased measurement of the neutral carbon cluster distribution remains elusive.

It has long been recognized that linear structures are stable for the small neutral carbon clusters, with the cumulenic configurations $(: C=C \cdots C=C:)$ preferred over the acetylenic $(\cdot C \equiv C$ $\mathrm{C} \cdot \mathrm{C} \equiv \mathrm{C} \cdot$ ) ones. ${ }^{1,5}$ Of these, the odd-numbered species are believed to possess ${ }^{1} \Sigma_{\mathrm{g}}{ }^{+}$electronic ground states, while the even-numbered species have ${ }^{3} \Sigma_{\mathrm{g}}^{-}$ground states. Additionally, the evennumbered species $\mathrm{C}_{4}, \mathrm{C}_{6}, \mathrm{C}_{8}$ and $\mathrm{C}_{10}$ are recognized to have cyclic structures of comparable or even greater stability compared to the linear species. Extensive computational studies have examined these neutral clusters ${ }^{34-49}$ and their corresponding ions. ${ }^{50-61}$ Spectroscopy has been applied to the neutral systems in the gas phase $\mathrm{e}^{1,5,62-64}$ and in matrix isolation experiments. ${ }^{1,5,65-70}$ More recent experiments have employed mass-selection prior to matrix spectroscopy., ${ }^{5,69,70}$ The 
various spectroscopy experiments have provided convincing evidence primarily for the linear structures. Anion clusters have been investigated with resonance-enhanced photodetachment spectroscopy, ${ }^{5,71-73}$ mass-selected photoelectron spectroscopy, ${ }^{5,74-76}$ and matrix infrared techniques,${ }^{77}$ but there is only limited data on the corresponding cations. ${ }^{78}$ However, ion mobility measurements have investigated both cations and anions and found evidence for both cyclic and linear structures, depending on the cluster size. ${ }^{79-80}$ Ionization potentials (IPs) provide an additional way to probe the electronic structure and bonding of these systems. In particular, an alternation in IP has been suggested as a way to confirm the suspected alternation in singlet versus triplet ground states for the linear species. ${ }^{5}$ Except for the case of $\mathrm{C}_{60},{ }^{81}$ only indirect experiments have been applied to carbon cluster ionization potentials, ${ }^{31}$ and there are also only a limited number of theoretical IP studies. ${ }^{47,55,56}$ Additionally, as shown below, ionization potentials can be significantly different for linear versus cyclic species. Measurements of the IP values as a function of cluster size may provide insight into the structures present and the bonding configurations for neutral carbon species.

As noted above, the ionization potentials of small carbon clusters lie in the 9-13 eV range, which corresponds to vacuum ultraviolet wavelengths. The ALS provides tunable radiation in this region, but significant experimental issues arise in coupling the quasi-continuous output of this source with the low repetition rate of typical cluster-beam experiments. Recent experiments by Nicolas and coworkers ${ }^{82}$ described how the pulsed-nozzle laser vaporization method can be combined with the ALS to obtain an ionization potential $(11.61 \mathrm{eV})$ for $\mathrm{C}_{3}$. Related experiments have recently investigated metal oxides using this same methodology. ${ }^{83}$ In the present work, we employ similar methods together with improvements in the cluster source and are able to obtain ionization thresholds for carbon clusters up to a size of $n=15$.

To extract the most meaningful conclusions from this ionization data, we have performed new electronic structure computations for the neutral and cation clusters at the highest level of theory yet applied. While there have been extensive theoretical studies examining neutral carbon clusters, ${ }^{34-49}$ the literature on the corresponding cations is somewhat sparse. ${ }^{50-57}$ Furthermore, 
there are only a limited number of studies specifically examining ionization potentials for the small cluster sizes. ${ }^{48,55,56}$ Giuffreda, Deleuze and Francois ${ }^{55}$ provided an extensive survey of structures, energies and electronic properties for $\mathrm{C}_{4}{ }^{+}$through $\mathrm{C}_{19}{ }^{+}$using two different density functional theory (DFT) methods. Coupled cluster theory including single and double excitations with a perturbative correction for triple excitations $[\operatorname{CCSD}(T)]$ paired with the cc-pVDZ basis set was further used to refine the energies at the optimized DFT geometries. The results, however, were somewhat inconsistent, with $\mathrm{DFT}$ and $\operatorname{CCSD}(\mathrm{T})$ often predicting quite different relative energies and ionization potentials. Similarly, in a study focused on doubly ionized clusters, Díaz-Tendero, Martín and Alcami ${ }^{56}$ presented first ionization potentials for $\mathrm{C}_{1}-\mathrm{C}_{9}$ based on B3LYP density functional theory and $\operatorname{CCSD}(\mathrm{T})$ single point energies computed at B3LYP or $\operatorname{CCSD}(\mathrm{T})$ geometries, both with the moderately sized 6-311+G(3df) basis set. While these results were in better agreement with the experiments than those of Giuffreda et al., ${ }^{55}$ the use of a single basis set means there are no data to judge the convergence of these results with respect to the completeness of the one-particle basis set. Moreover, the extensive reliance on DFT optimized geometries in both of these previous studies casts some doubt on the accuracy of the reported IPs. In a series of papers, Deleuze and coworkers ${ }^{55}$ predicted valence ionization spectra of small carbon rings and linear chains based on one-particle Green's function techniques, concluding that characteristics of ionization spectra could be used to differentiate between cyclic and linear isomers.

In the present study, we employ the focal point method of Allen and coworkers ${ }^{84-85}$ to study the ionization potentials of both linear and cyclic carbon clusters in the small size range. This methodology makes it possible to extrapolate systematically to the complete one-particle basis set limit, providing the most reliable predictions to date for these ionization potentials. As shown below, we find that ionization potentials do vary significantly for different isomers at the same cluster size. This combined experimental and theoretical study provides new insight into the size distribution of neutral carbon clusters and the structures of the species expected to be present under different conditions. 


\section{Experimental Section}

These experiments employ a high repetition rate pulsed-nozzle laser ablation cluster source to produce the carbon clusters. Photoionization of these clusters is accomplished with the tunable VUV output of the Advanced Light Source (ALS) operating in the 8-13 eV range. The experiments take place at the Chemical Dynamics Beamline ${ }^{86}$ using its 3 meter monochromator. The cluster beam produced in the source chamber is collimated with a $1 \mathrm{~mm}$ skimmer and photoionization takes place in a differentially-pumped detection chamber. The VUV beam intersects the cluster beam in the ion source region of a reflectron time-of-flight mass spectrometer (R.M. Jordan Co.), which analyzes and detects the resulting cations. Many of the

details of the experiment were described previously. ${ }^{82-83}$

The key feature of the experiment is the high repetition rate source and how it couples to the quasi-continuous output (500 MHz) of the ALS. The source employs a piezo-electric valve operating at $100 \mathrm{~Hz}$ with a helium expansion gas. A rotating/translating carbon rod sample is ablated with the focused output of a pulsed Nd:YAG laser (Coherent Infinity), operating at 532 $\mathrm{nm}$ and synchronized with the nozzle pulse. The typical energy of the laser pulse is $5-10 \mathrm{~mJ}$, which is focused to a spot size of about $1.5 \mathrm{~mm}$. Ions produced directly from the cluster source are blocked with deflection plates located just before the skimmer. The neutral clusters pass through the ionization source of the mass spectrometer, where they are intersected with the quasi-continuous VUV output of the ALS. The acceleration plates of the mass spectrometer are pulsed at the arrival time of the cluster beam to sample any ions produced. The output of the microchannel plate detector is collected with a multichannel scaler card (FAST Comtec 7886) as the VUV is scanned to record the photoionization efficiency (PIE) spectra. Because of the low signal levels, these spectra required extensive averaging. Low resolution scans were measured with an ALS step size of $0.2 \mathrm{eV}$, while higher resolution scans were measured with a step size of $0.05 \mathrm{eV}$. At each energy step, mass spectra were averaged for 8000 pulses of the vaporization laser. Scans for each cluster size were assembled from the stored mass spectra by extracting 
specific mass channels versus the energy, and then 2-3 of the best of these (judged by cluster source stability) scans were averaged.

\section{Theoretical Methods}

Precise ionization potentials and relative energies for linear and cyclic carbon clusters $\left(\mathrm{C}_{4}-\mathrm{C}_{10}\right)$ were predicted using the focal point method of Allen and coworkers. ${ }^{84,85}$ The focal point procedure provides a framework within which one executes dual one- and n-particle expansions, as detailed previously. ${ }^{85}$ Extrapolations to the complete one-particle basis set limit use the correlation consistent hierarchy of atom-centered Gaussian-type basis sets (cc-pVXZ; $X=$ $\mathrm{D}, \mathrm{T}, \mathrm{Q}, 5) .{ }^{87}$ Electron correlation is accounted for primarily using coupled cluster theory including single and double excitations with a perturbative correction for connected triple excitations $[\mathrm{CCSD}(\mathrm{T})]{ }^{88,89}$ In selected cases (cyclic $\mathrm{C}_{4}$ and linear and cyclic $\mathrm{C}_{5}$ ) for which the extrapolated contributions to the IP from the (T) correction were particularly large, an additional correction was appended based on coupled cluster theory with single, double and full triple excitations (CCSDT) $)^{90-92}$ with the cc-pVDZ basis set. All CCSD(T) energy computations were carried out using MOLPRO, ${ }^{93}$ while ACES II ${ }^{94}$ was utilized for the evaluation of CCSDT energies. The functional form ${ }^{95}$ used for the basis set extrapolation of Hartree-Fock energies was

$$
E_{H F}=a+b e^{-c X},
$$

while the correlation energies were extrapolated via ${ }^{96}$

$$
E_{c o r r}=a+b X^{-3} \text {. }
$$

For all open-shell systems, the reference wavefunction was computed using restricted open-shell Hartree-Fock (ROHF) theory to avoid potential problems resulting from a spin contaminated reference wavefunction. Pseudosemicanonical orbitals ${ }^{97}$ were used in all openshell CCSD(T) computations and the frozen-core approximation invoked throughout. Exploratory computations for selected systems revealed that the influence of core correlation on the IPs was well below $0.1 \mathrm{eV}$, so these effects were not considered further. Energies for focal point analyses were computed at geometries optimized using $\operatorname{CCSD}(\mathrm{T})$ theory paired with the 
cc-pVTZ basis set for all clusters considered except $\mathrm{C}_{9}$ and $\mathrm{C}_{10}$, for which the cc-pVDZ basis set was used. The geometry optimizations were executed with ACES II.

\section{Results and Discussion}

Figure 1 shows mass spectra accumulated for a carbon cluster distribution ionized at the two VUV energies of 10.0 and $12.0 \mathrm{eV}$. The cluster source and mass spectrometer conditions were the same for these two measurements; the only difference is the ionizing wavelength. As shown, carbon clusters out to a size of at least 15 atoms are detected, as well as impurity peaks from acetone (from a previous rinse of the beam gas lines) and aluminum atoms ablated from the sample rod holder. The relative intensities of the mass peaks detected are not uniform, but vary with cluster size. These intensity differences are reproducible for different mass spectra accumulated at these ionization energies. At the $10.0 \mathrm{eV}$ energy, the $\mathrm{C}_{10}{ }^{+}, \mathrm{C}_{12}{ }^{+}$, and $\mathrm{C}_{14}{ }^{+}$masses are prominent, and the smaller cluster masses are not present. However, at the $12.0 \mathrm{eV}$ energy, new peaks for $\mathrm{C}_{3}{ }^{+}, \mathrm{C}_{5}{ }^{+}, \mathrm{C}_{6}{ }^{+}$and $\mathrm{C}_{7}{ }^{+}$are detected, with $\mathrm{C}_{3}{ }^{+}$becoming the largest peak in the spectrum. The appearance of $\mathrm{C}_{3}{ }^{+}$in the $12.0 \mathrm{eV}$ spectrum but not in the $10.0 \mathrm{eV}$ data is consistent with its ionization threshold, which was recently measured to be $11.61 \mathrm{eV}{ }^{82}$ At both wavelengths, the even-numbered clusters in the higher size range $(n=9-15)$ are more prominent than the odd-numbered ones. This data can be compared to the mass spectra recently measured in other labs at the $118 \mathrm{~nm}$ wavelength. ${ }^{32,33}$ Although the spectra in these studies varied considerably with source conditions, the $n=10,12$ and 14 mass peaks were prominent under many conditions, as seen here. In the $118 \mathrm{~nm}$ data, small carbon ions were observed (e.g., $\mathrm{C}_{3}^{+}$) at the $10.5 \mathrm{eV}$ energy and this signal was attributed to the presence of metastable excited states of $\mathrm{C}_{3}$ in the beam. We do not see such a signal, apparently indicating that any excited states for these clusters high enough to cause ionization at such a low energy have been collisionally or radiatively relaxed before we probe them in the mass spectrometer. 


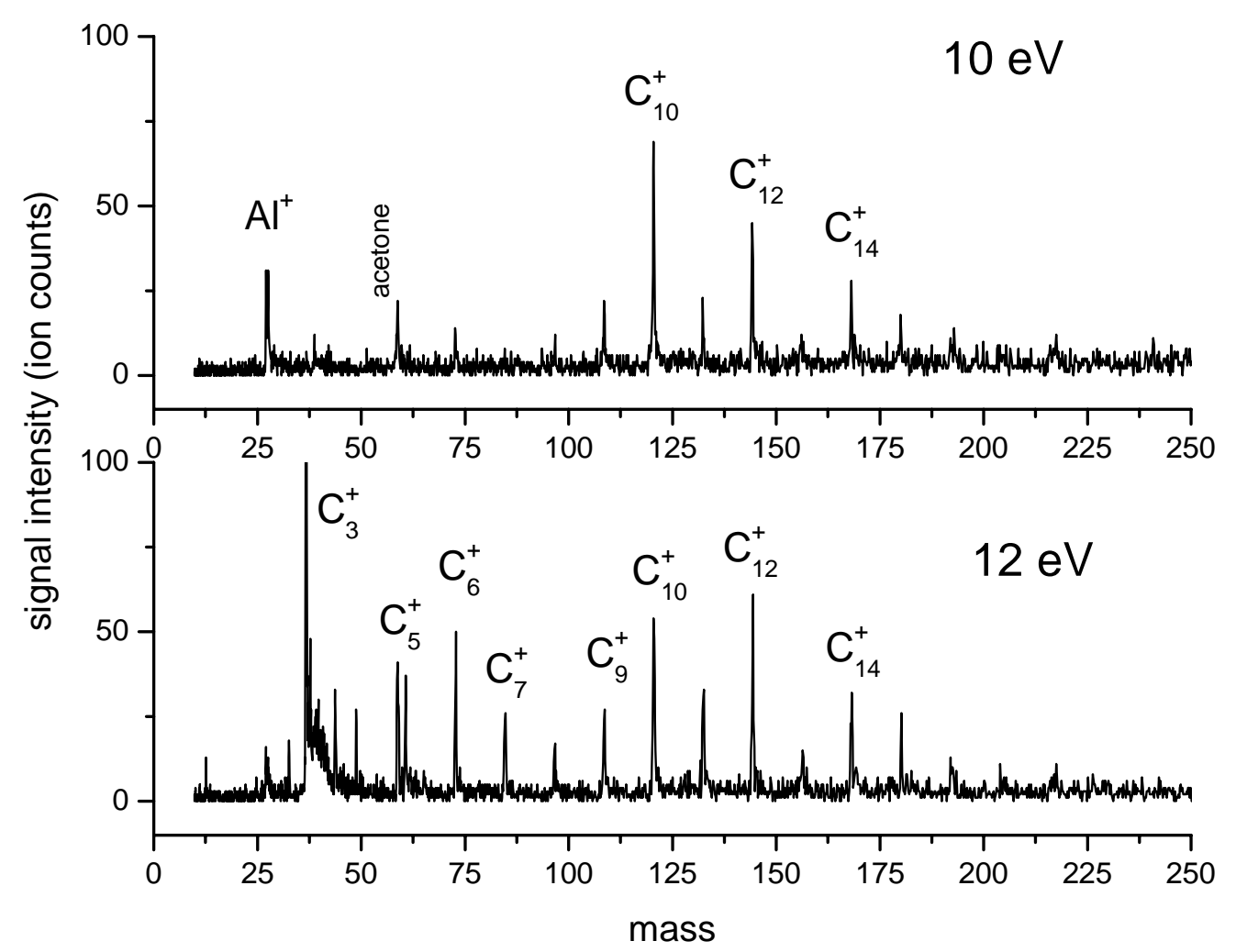

Figure 1. The mass spectra measured at the photon energies of 10.0 and $12.0 \mathrm{eV}$. The tail apparent just after $\mathrm{C}_{3}$ is due to impurity masses in this region, including potassium (39 amu) and some $\mathrm{C}_{3} \mathrm{H}_{\mathrm{n}}$ species.

Figure 2 shows the mass spectrum at the slightly higher ionizing energy of $12.6 \mathrm{eV}$. In this spectrum, new impurity masses are seen for water and molecular oxygen. The appearance of these species at $12.6 \mathrm{eV}$ but not at $12.0 \mathrm{eV}$ is consistent with their known ionization potentials (12.6 and $12.1 \mathrm{eV}$ respectively). ${ }^{98}$ The relative intensities of cluster mass peaks in the higher range is about the same as that seen at $12.0 \mathrm{eV}$. However, the most obvious difference between the $12.0 \mathrm{eV}$ data and the $12.6 \mathrm{eV}$ data is the dramatic increase in the mass feature corresponding to $\mathrm{C}_{3}{ }^{+}$. This peak is roughly $2-3$ times larger at the $12.6 \mathrm{eV}$ ionization energy, making it by far the most dominant peak in the mass spectrum. In laser ionization experiments, mass spectral intensities are sometimes found to vary with photon energies because of the effects of multiphoton absorption and consequent fragmentation, but the photon flux from the ALS is so low that only single photon events are possible. Therefore, the best explanation for the change in the $\mathrm{C}_{3}{ }^{+}$ion intensity at these two energies is that the cross section for ionization is energy dependent. The energy dependence of this cross section has been reported previously, ${ }^{82}$ 


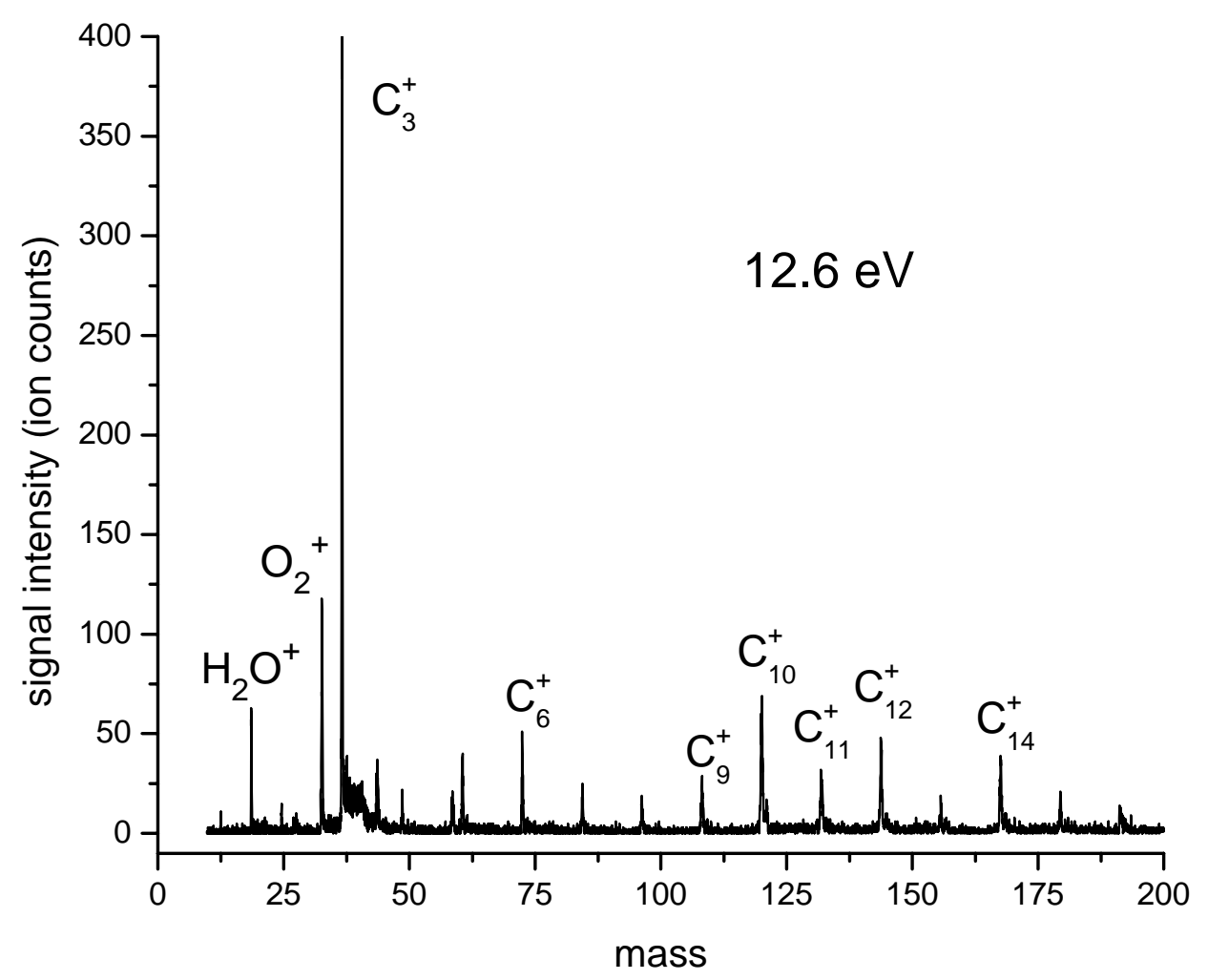

Figure 2. The mass spectrum measured at the photon energy of $12.6 \mathrm{eV}$.

and there is indeed a significant increase after $12.5 \mathrm{eV}$. Another consideration is the possibility that VUV induced photofragmentation of larger clusters that might add to the intensity of the $\mathrm{C}_{3}{ }^{+}$ channel. For example, both $\mathrm{C}_{5}{ }^{+}$and $\mathrm{C}_{6}{ }^{+}$species produce $\mathrm{C}_{3}{ }^{+}$via fragmentation. ${ }^{23-30}$ However, the thresholds for these fragmentation processes lie at $4-5 \mathrm{eV},{ }^{30}$ and so these processes could not contribute to the $\mathrm{C}_{3}{ }^{+}$channel until the photon energy is at least this far above the ionization thresholds of these clusters. As we show below, the ionization thresholds for $\mathrm{C}_{5}$ and $\mathrm{C}_{6}$ lie in the 9.5-10.0 eV range, and therefore one photon ionization accompanied by fragmentation would not be expected until photon energies above about $14 \mathrm{eV} . \mathrm{C}_{3}$ elimination by fragmentation of larger clusters is in the form of the neutral, ${ }^{23-30}$ which would not contribute ion signal here. The intensity of the $\mathrm{C}_{3}{ }^{+}$peak is therefore due only to the abundance of the neutral and its specific ionization efficiency at these different energies.

The large intensity of the $\mathrm{C}_{3}{ }^{+}$mass peak implies that the density of $\mathrm{C}_{3}$ produced in this experiment is quite high compared to that of the other clusters. This is perhaps not too surprising because previous work has long suggested that this is the most abundant molecule in the vapor above carbon in a vacuum, ${ }^{1,5}$ and it is well known that $C_{3}$ is a stable neutral fragment in the 
decomposition of small carbon clusters. ${ }^{23-30}$ However, ours is the first experiment with photon energies great enough to detect the small carbon clusters produced in such a laser vaporization experiment. It is also interesting that we detect only a very small intensity for $\mathrm{C}_{2}{ }^{+}$. The ionization potential of $\mathrm{C}_{2}$ has been problematic to determine, but it is generally believed to lie at or below $12.1 \mathrm{eV} .^{98,99}$ Therefore, $\mathrm{C}_{2}$ could be detected at $12.6 \mathrm{eV}$ if it is present in significant density, but it is not. This data indicates that the neutral carbon vapor produced by laser vaporization contains more $\mathrm{C}_{3}$ than $\mathrm{C}_{2}$. This is significant, because fullerenes and carbon nanotubes are grown from similar laser-generated plasmas (although catalysts are required for nanotubes). The most recent simulations available for the growth of these species assume that $\mathrm{C}_{2}$ is the dominant vapor species involved. ${ }^{15}$ Based on the results here, this assumption needs to be re-evaluated. It is of course true that cluster growth in a laser source is quite complex, involving many steps of growth and decomposition, and the distribution obtained in any given experiment may vary with vaporization laser and collisional gas conditions. However, the conditions employed here are typical of such sources.

To investigate the threshold ionization behavior for these clusters, we scanned the ALS energy while recording mass spectra like those shown here at each energy step. In low resolution experiments, we employed $0.2 \mathrm{eV}$ steps, while in higher resolution experiments we employed $0.05 \mathrm{eV}$ steps. The resulting ionization efficiency spectra were essentially the same for both settings. The full set of data for all the cluster sizes is collected in the Supporting Information for this article. We show selected examples of this data here.

Figures 3-8 show the ionization efficiency spectra in the threshold region for the $\mathrm{C}_{4}, \mathrm{C}_{5}$, $\mathrm{C}_{6}, \mathrm{C}_{7}, \mathrm{C}_{9}$ and $\mathrm{C}_{10}$ clusters. These spectra represent the average of 2-3 individual scans, with vertical error bars representing the standard errors in this averaging. In each of these spectra, an expanded inset is shown to illustrate how the ionization threshold is derived. A linear fit is employed to determine the average base-line just before the onset of signal, and then a similar linear fit is employed to the rising ion signal level above the onset. The intersection of these lines is defined as the experimental ionization threshold for each cluster. The values determined 
this way for the various cluster sizes are presented in Table 1. Because of the inherent noise level in the experiment and the step size employed for scanning, the uncertainty in these thresholds caused by the noise level in the experiment is estimated to be $\pm 0.1 \mathrm{eV}$. However, it is clear that the threshold we detect depends on the overall size of the carbon cluster signal in each experiment, because the signal is rising gradually out of the background. We use extensive averaging and multiple scans to be sure that we have measured the first onset in a reproducible way with the signal levels available. We have also attempted to use other expansion gases (nitrogen, argon) to improve the cluster yield, but were not able to make these clusters efficiently under those conditions. Each of these threshold spectra has a dip in intensity at $11.8 \mathrm{eV}$. This is due to a reduction in the transmitted VUV light caused by the argon gas filter used to block higher harmonics of the ALS. ${ }^{86}$ We do not normalize to the VUV intensity, because it is difficult to measure this at the interaction region of the mass spectrometer. Some of the spectra also exhibit minor dips in intensity near 10.5 and $11.2 \mathrm{eV}$. This was caused by a momentary drop in signal from the cluster source at these energies in these scans.

The ionization thresholds determined here fall mostly in the range of 9-10 eV. There is a general trend toward lower energies as cluster size increases, with the highest value occurring for $\mathrm{C}_{3}$ at $11.6 \mathrm{eV}$ and the lowest for $\mathrm{C}_{12}$ at $8.4 \mathrm{eV}$. The threshold for $\mathrm{C}_{3}$ was investigated thoroughly in previous work from this group, ${ }^{82}$ and the present data are completely consistent with the earlier experiments. Except for this, there are no previous data for photoionization thresholds of these small carbon clusters. However, this data can be compared to ionization potentials determined previously by Eyler and coworkers using charge transfer bracketing experiments, ${ }^{31}$ and to more limited data from electron impact ionization by Benedikt et al. ${ }^{100}$ The IP values determined from these previous experiments are also given in Table 1 for comparison to the present data. As shown, the agreement between the charge transfer bracketing (CTB) experiments and the present threshold photoionization (TPI) experiments is not particularly good. The CTB values are higher than the TPI values for the $n=3-6$ clusters and lower for the $\mathrm{n}=7-11$ and $13-15$ species. Only for the $\mathrm{n}=6,10,12$ and 14 clusters do the two techniques agree 


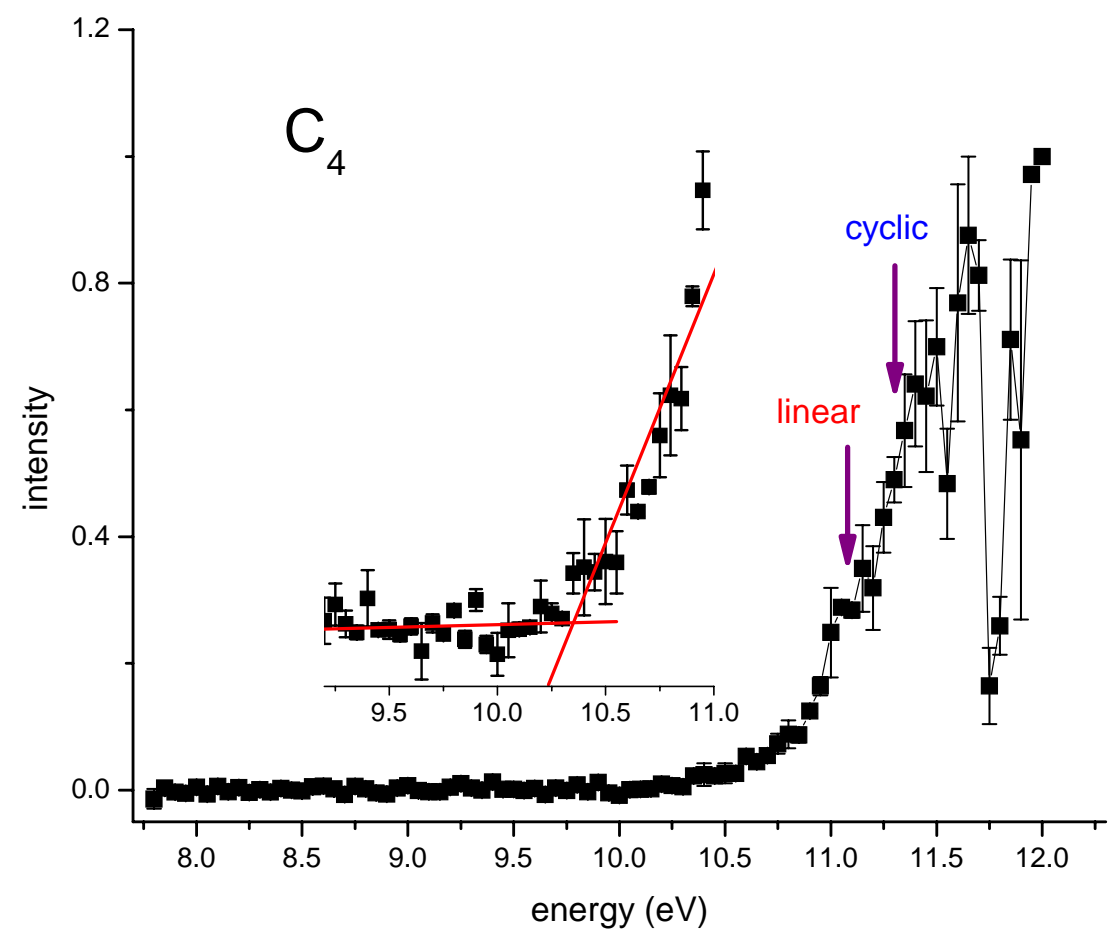

Figure 3. The photoionization efficiency curve in the threshold region for $\mathrm{C}_{4}$. The arrows show the positions of the calculated vertical IP for the two different isomers. The blue lettering indicates the isomer computed to be more stable, and the red indicates the less stable one.

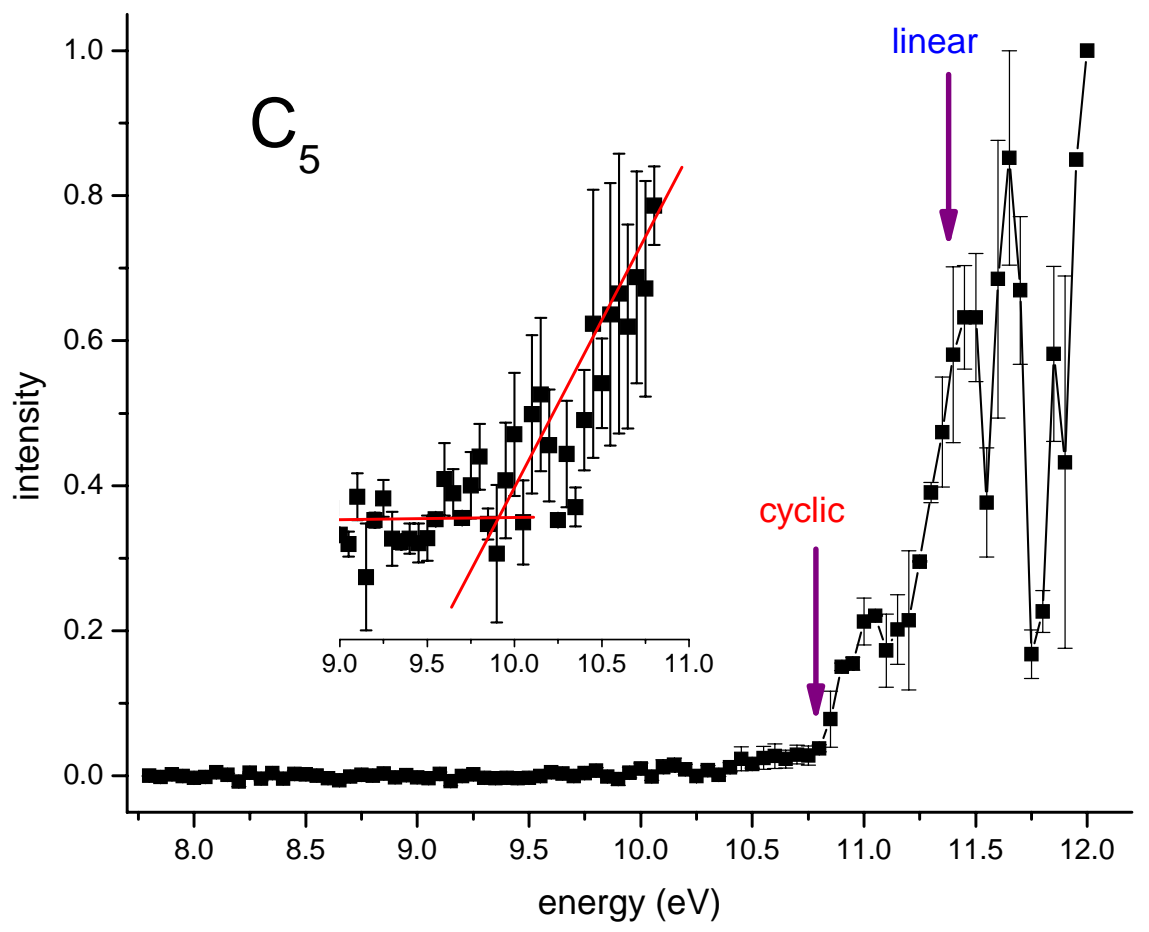

Figure 4. The photoionization efficiency curve in the threshold region for $\mathrm{C}_{5}$. The arrows show the positions of the calculated vertical IP for the two different isomers. The blue lettering indicates the isomer computed to be more stable, and the red indicates the less stable one. 


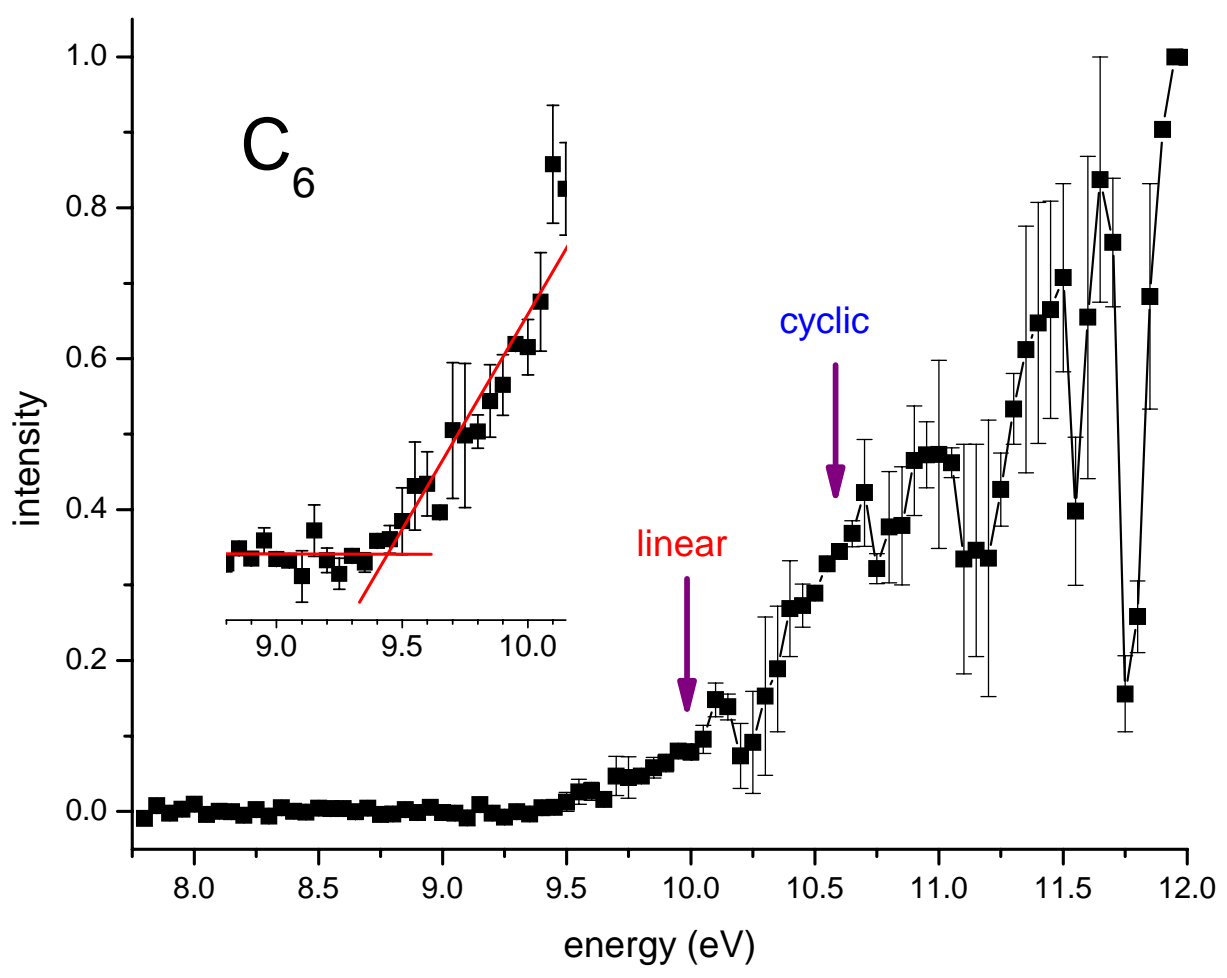

Figure 5. The photoionization efficiency curve in the threshold region for $\mathrm{C}_{6}$. The arrows show the positions of the calculated vertical IP for the two different isomers. The blue lettering indicates the isomer computed to be more stable, and the red indicates the less stable one.

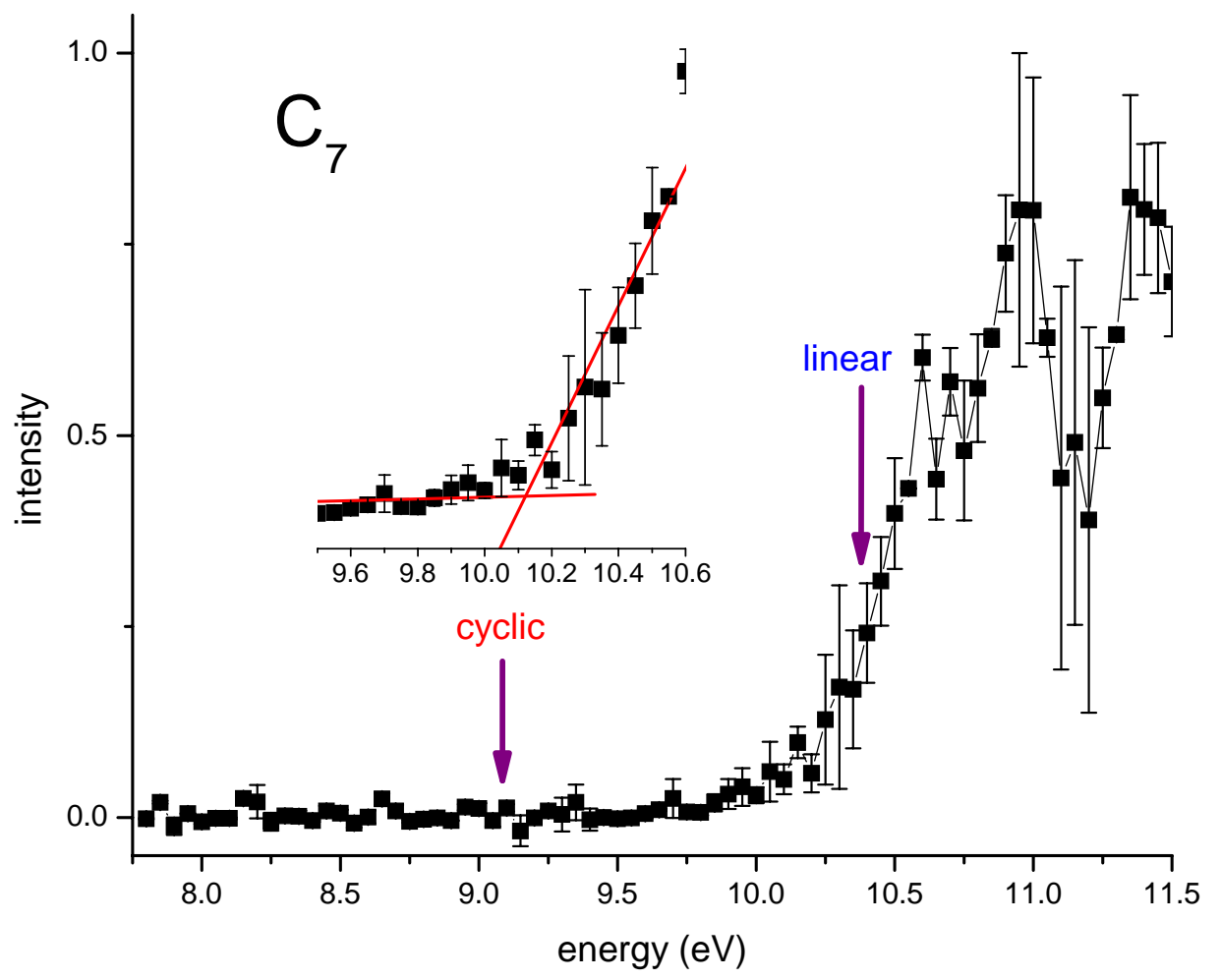

Figure 6. The photoionization efficiency curve in the threshold region for $\mathrm{C}_{7}$. The arrows show the positions of the calculated vertical IP for the two different isomers. The blue lettering indicates the isomer computed to be more stable, and the red indicates the less stable one. 


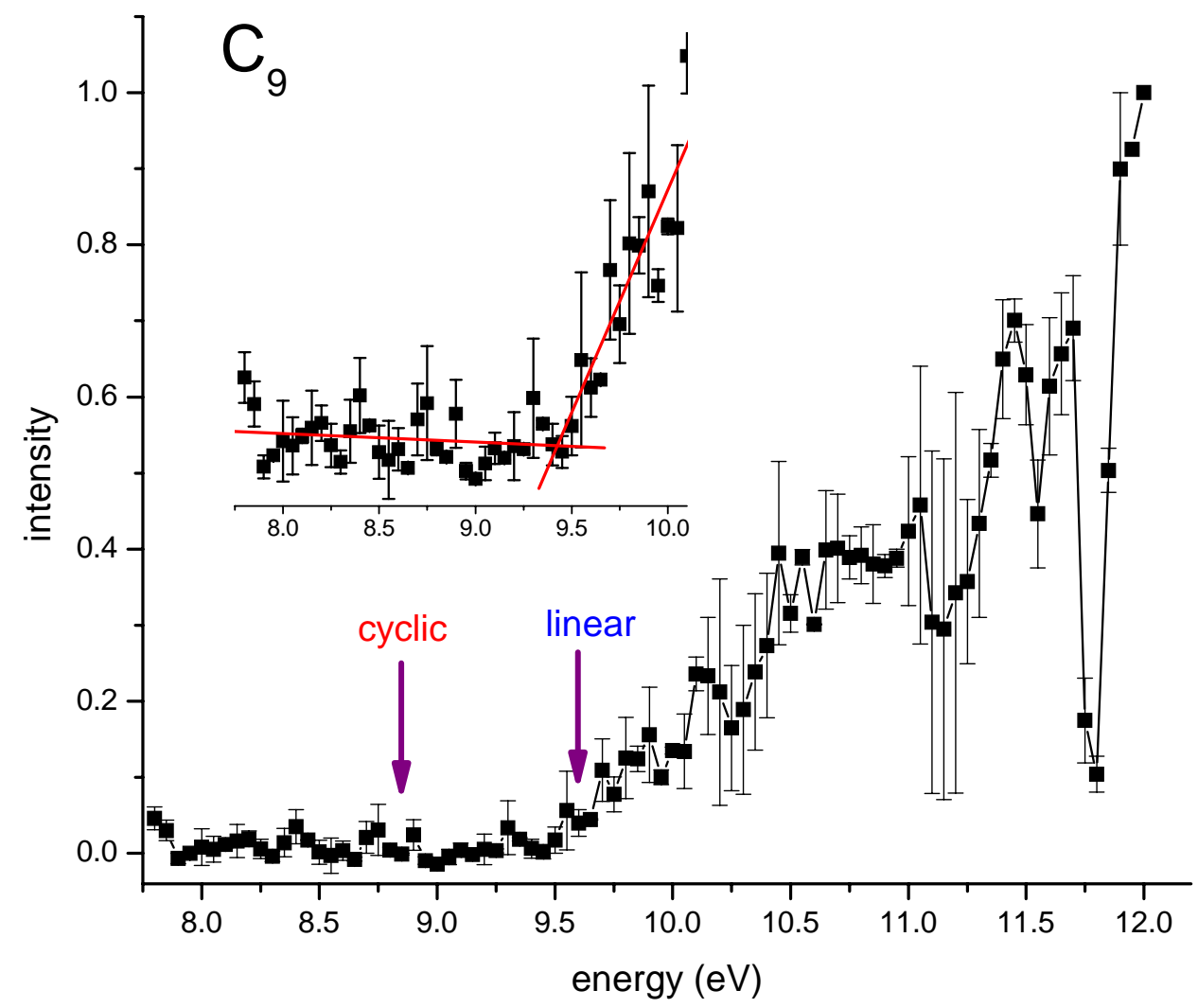

Figure 7. The photoionization efficiency curve in the threshold region for $\mathrm{C}_{9}$. The arrows show the positions of the calculated vertical IP for the two different isomers. The blue lettering indicates the isomer computed to be more stable, and the red indicates the less stable one.

within overlapping error bars. The electron impact (EI) ionization experiments also determined thresholds that are higher than ours. However, a variety of factors influence the values measured in these different experiments, and careful consideration is required before drawing any conclusions from these discrepancies.

Charge transfer bracketing, electron impact ionization and photoionization experiments are all limited by the energy dependent efficiencies of the methods employed and by the conditions of the clusters in these respective experiments. As is evident in the figures here, the TPI signals for some clusters are relatively small and they do not rise sharply out of the baseline. It is therefore conceivable that the actual thresholds lie at energies slightly lower than those derived here, and that these lower onsets could be detected if the signal levels were larger. Franck-Condon factors in the ionization process could also cause the signals detected to lie at energies higher than the adiabatic ionization potential. The adiabatic ionization potential $\left(\mathrm{IP}_{\mathrm{a}}\right)$ is 


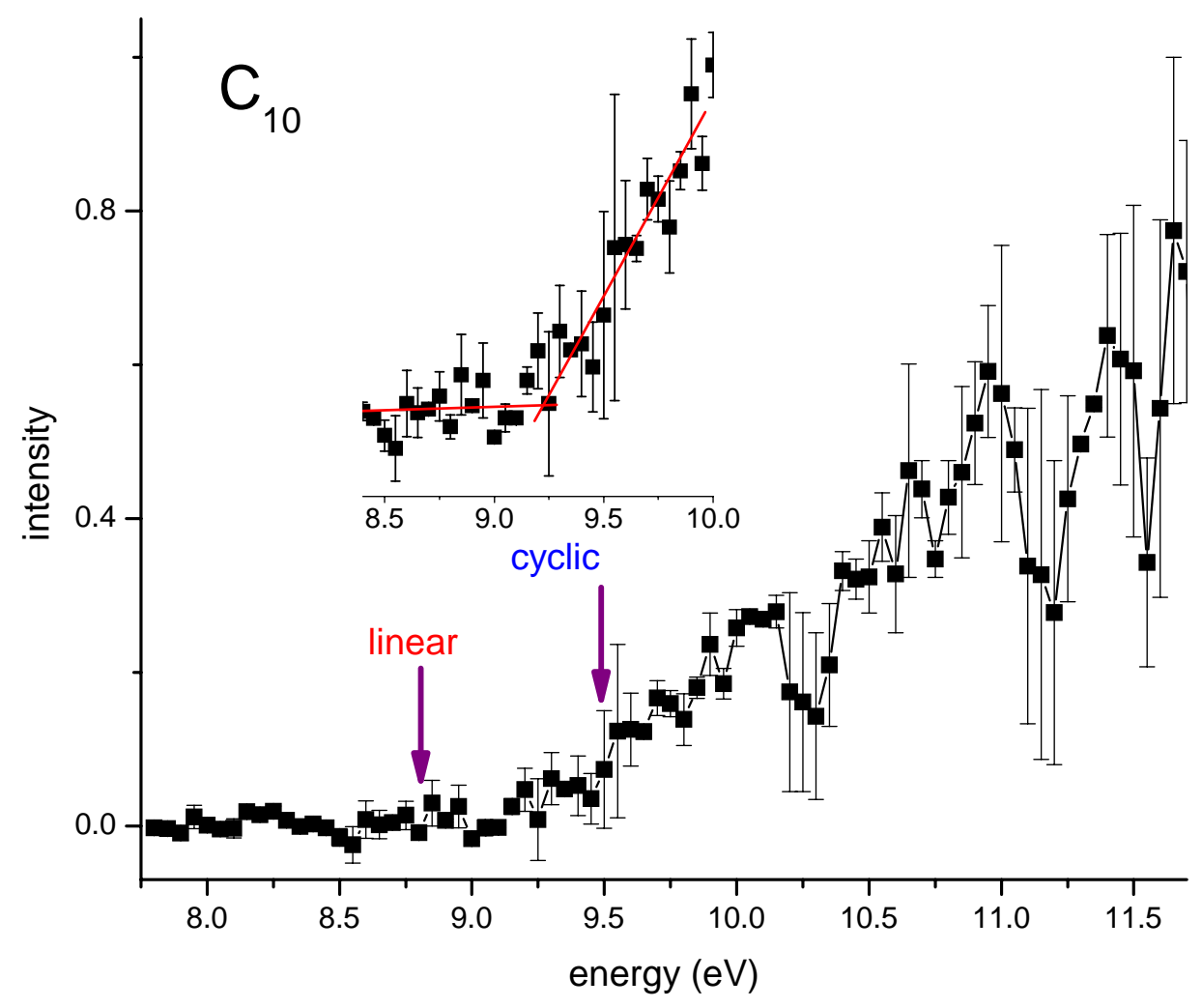

Figure 8. The photoionization efficiency curve in the threshold region for $\mathrm{C}_{10}$. The arrows show the positions of the calculated vertical IP for the two different isomers. The blue lettering indicates the isomer computed to be more stable, and the red indicates the less stable one.

defined as the minimum energy between the ground state neutral and the ground state cation. The vertical ionization potential $\left(\mathrm{IP}_{\mathrm{v}}\right)$ is defined as the most probable transition from the ground state neutral to the corresponding cation at that same geometry. However, the signal here, which rises from zero to some detectable level, is likely to fall between these two values. Because of these considerations, the signals detected here in these TPI experiments must be regarded as upper limits to the true adiabatic ionization energies. Unfortunately, the CTB and EI experiments are subject to similar problems. The efficiency of charge transfer may also vary with energy because of Franck-Condon factors in the ionization of the neutral collision partner, possible barriers in the charge transfer, etc. CTB and EI experiments therefore also provide numbers that represent upper limits to the true ionization potentials. The temperature of the ions in each experiment can also affect the measured threshold energies in the opposite direction; if ions are internally hot, the measured thresholds may be slightly lower than the true values. Because of the propensities for $\Delta \mathrm{v}=0$ vibrational transitions and small $\Delta \mathrm{J}$ transitions in 
ionization, ${ }^{101}$ such vibrational and rotational effects are not usually large. However, these clusters are well known to have low lying excited electronic states, and because their production processes involve plasma chemistry, such states may be populated in the cluster growth. In our experiment, states that are radiatively coupled with the ground state will relax during the transit time from the source to the interrogation region (a few hundred microseconds), but states with no allowed radiative decay route may survive and influence the measurements. Our experiment employs collisions with the helium expansion gas to relax thermal energy and to promote cluster growth. However, it is well known that metastable excited states can sometimes survive in spite of collisional cooling.

Closely related to temperature in this carbon system is the role of isomers. As we discuss further below, both linear and cyclic isomers are expected for each of these clusters. The relative amounts of each present under experimental conditions depends on both their energies and entropies. In particular, because entropy favors the linear structures, greater temperatures increase the relative amounts of the linear isomers present. We expect (and confirm below) that different isomers have different ionization potentials. It is also true that the most stable structure at some cluster sizes is not the same for the neutral and corresponding cation. The TPI experiment here (and the previous EI experiment) begins with neutral clusters, whereas the CTB experiment begins with selected cations. It is therefore likely for at least some cluster sizes that these two experiments are probing different isomeric species. Because of these issues, the comparison of the TPI, EI, and CTB experiments is provided below on a case-by-case basis for each cluster size.

To further investigate the electronic structures and isomers for these clusters, and the role of these on ionization energetics, we have performed new ab initio computations on the small clusters in the size range $n=4-10$ using the focal point method described above. Although there have been many previous computations on carbon clusters, ${ }^{34-61}$ there have been few examinations of both neutrals and cations with the same high level of treatment. For each cluster size, the structure was optimized for both the neutral and the corresponding cation using 
$\operatorname{CCSD}(\mathrm{T})$ theory. Final energy differences were determined via focal point extrapolations to obtain both adiabatic and vertical ionization potentials. No zero point vibrational corrections were included, because vibrational frequency calculations are problematic for many of these species at this level of theory (due to both computational demands and intricacies such as electronic symmetry breaking) and zero point corrections are estimated to be small $(<0.05 \mathrm{eV})$.

Consistent with previous work, both linear and cyclic structures are found for each cluster size in both the neutrals and the cations for which computations were done $(n=4-10)$. Figure 9 qualitatively depicts the cyclic structures found for the neutral clusters. More extensive figures and tables giving internal and Cartesian coordinates for all species are contained in Supporting Information. Table 2 presents the relative energies for the cyclic and linear structures for these neutrals and ions. As shown, and also consistent with previous work, the odd-numbered neutral clusters prefer linear structures, while the even numbered neutrals prefer cyclic structures. The same trend is found for the small cations, but this switches over for $\mathrm{C}_{7}^{+}$and $\mathrm{C}_{9}^{+}$. Specifically, both the $\mathrm{C}_{7}$ and $\mathrm{C}_{9}$ neutrals have linear structures, but the ions lie lower in energy for cyclic configurations. This characteristic of these clusters has been documented previously, particularly in ion mobility experiments on the cations. ${ }^{79-80}$

Table 3 contains predicted adiabatic IPs from the present work and those of Guiffreda et al. ${ }^{55 \mathrm{a}}$ and Díaz-Tendero et al. ${ }^{56}$ Comparing the presently computed cc-pVDZ CCSD(T) IPs with those of ref $53 \mathrm{a}$, we see only minor differences, with the exception of linear $\mathrm{C}_{4}, \mathrm{C}_{6}$, and $\mathrm{C}_{8}$. The present results are evaluated at cc-pVTZ CCSD(T) optimized geometries [or cc-pVDZ CCSD(T) for $\mathrm{C}_{9}$ and $\mathrm{C}_{10}$ ], while those of Guiffreda et al. ${ }^{55 \mathrm{a}}$ are computed at B3LYP geometries. The use of $\operatorname{CCSD}(\mathrm{T})$ optimized geometries is seen to have some effect on the predicted IPs, generally around $\pm 0.1 \mathrm{eV}$. For linear $\mathrm{C}_{4}, \mathrm{C}_{6}$, and $\mathrm{C}_{8}$ there are considerable gaps between our cc-pVDZ $\operatorname{CCSD}(\mathrm{T})$ results and those of ref 55a; in each case our IP is more than $1 \mathrm{eV}$ larger. The absolute energies reported by Guiffreda et al. for the corresponding linear cationic clusters are quite close to our computed values, indicating that the energies for the neutral linear $\mathrm{C}_{4}, \mathrm{C}_{6}$, and $\mathrm{C}_{8}$ (which were not reported in ref 55a) must be the source of the discrepancy. However, using the B3LYP 

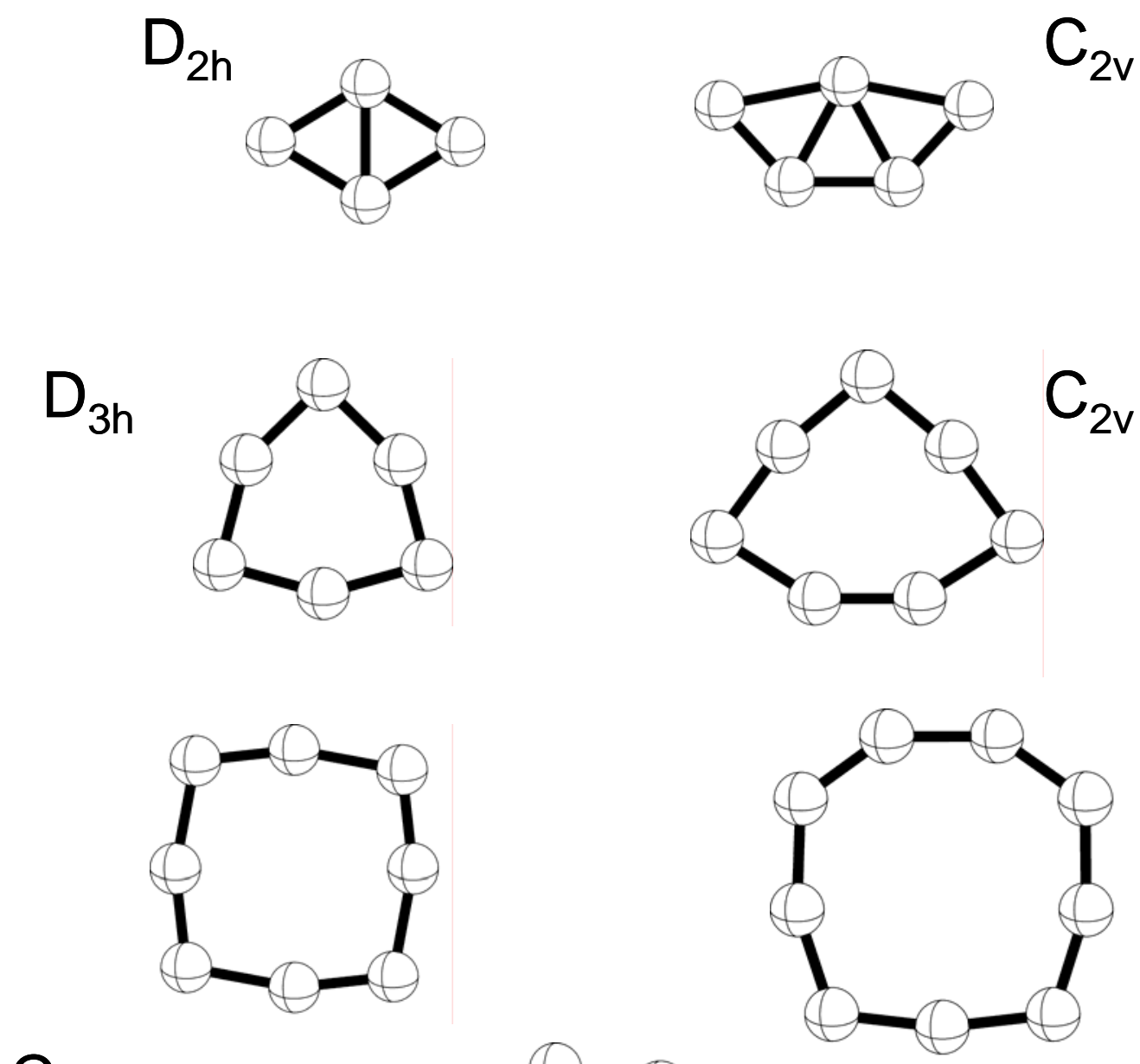

$C_{4 h}$

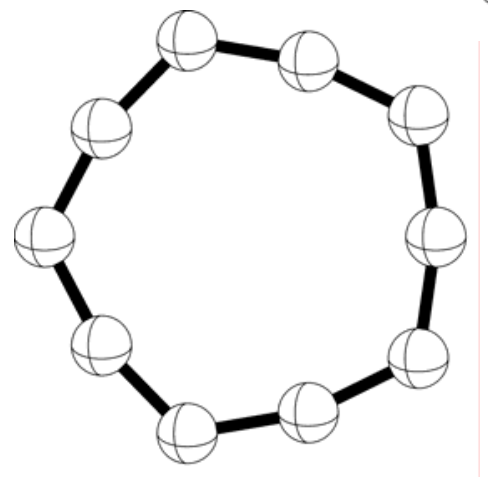

$\mathrm{C}_{2}$

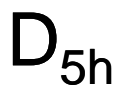

Figure 9. The cyclic structures calculated for the $\mathrm{C}_{4}-\mathrm{C}_{10}$ neutral clusters.

optimized geometries of Guiffreda et al., ${ }^{55 \mathrm{a}}$ we were unable to reproduce their reported IPs for these three systems. The source of this discrepancy is therefore unclear.

While the use of $\operatorname{CCSD}(\mathrm{T})$ geometries versus B3LYP geometries results in minor differences in predicted IPs, the use of larger basis sets yields substantial and systematic changes. Compared to the cc-pVDZ CCSD(T) results, utilization of the much larger cc-pVQZ basis set 
yields dramatic increases in predicted IPs. This increase is consistently above $0.2 \mathrm{eV}$ for the cyclic clusters and $0.5 \mathrm{eV}$ or more for the linear clusters. The increase in predicted IPs upon use of a larger basis set is due to an apparently protracted convergence of the neutral carbon cluster energies with respect to basis set completeness. The very small cc-pVDZ basis set is inadequate for a proper description of the electronic structure of the neutral clusters. The cc-pVQZ CCSD(T) IPs are consequently significantly larger than those reported by Guiffreda et al. ${ }^{55 a}$ The reliance on the cc-pVDZ basis for the computation of $\operatorname{CCSD}(T)$ energies in that work led to significant errors in predicted IPs, particularly for the linear carbon clusters. These errors are in addition to those for the linear $\mathrm{C}_{4}, \mathrm{C}_{6}$, and $\mathrm{C}_{8}$ discussed above. Without explicitly considering the convergence of results with respect to basis set completeness, significant errors can remain in what might otherwise appear to be reliable computations. The use of CCSD(T) alone does not guarantee accuracy - the quality of the basis set for the systems being studied must be carefully considered as well.

Our final recommended IPs, predicted using the focal point extrapolation approach, are slightly higher than or equal to the explicitly computed cc-pVQZ CCSD(T) values. At this level of theory the computed IPs are well converged with respect to basis set completeness and the inclusion of electron correlation. The predictions should be reliable to within $0.2 \mathrm{eV}$ for all species but linear $\mathrm{C}_{5}$. For linear $\mathrm{C}_{5}$ a large correction to the predicted $\mathrm{IP}$ of $+0.26 \mathrm{eV}$ was derived from the difference between cc-pVQZ CCSDT and $\operatorname{CCSD}(\mathrm{T})$ energies, suggesting that even with the full inclusion of triple excitations the predicted IP is not converged with respect to electron correlation. Details of this convergence of the presently predicted IPs can be seen in the focal point tables, which are available as Supporting Information.

Density functional theory performs quite well in predicting IPs for small carbon clusters, as seen by comparing the B3LYP results of Guiffreda et al. ${ }^{55 a}$ and Díaz-Tendero et al. ${ }^{56}$ with the focal point results. For most of the clusters considered, B3LYP paired with either the cc-pVDZ or $6-311+\mathrm{G}(3 \mathrm{df})$ basis set yields results within $0.2 \mathrm{eV}$ of the focal point values. In fact, these B3LYP values are consistently more accurate than the cc-pVDZ CCSD(T) results of Guiffreda 
et al. This seemingly strange occurrence is due to the profound basis set sensitivity of the $\operatorname{CCSD}(\mathrm{T})$ energies for the neutral clusters. For cyclic $\mathrm{C}_{8}$, the disparity of B3LYP with respect to our focal point values is $0.4 \mathrm{eV}$. There are also significant differences between B3LYP and our focal point values for linear $\mathrm{C}_{5}$ and $\mathrm{C}_{7}$, arising from the use of symmetry-broken linear carbon chains in ref 55a. In the present work and that of Díaz-Tendero et al., ${ }^{56} \mathrm{D}_{\infty \mathrm{h}}$-symmetric linear geometries are used, since the non-symmetric $\mathrm{C}_{5}$ and $\mathrm{C}_{7}$ geometries of Guiffreda et al. ${ }^{55 \mathrm{a}}$ appear to be the result of artifactual symmetry breaking, resulting from orbital instabilities in the Hartree-Fock wavefunction. ${ }^{102}$

The electronic structures of neutral and cationic carbon clusters are rife with confounding complications: ${ }^{1,5}$ electronic symmetry breaking, ${ }^{102}$ biradical character, numerous low-lying electronic states, and Jahn-Teller effects all complicate the straightforward application of standard single-reference electronic structure methods. To gauge the degree of multireference character in the carbon clusters studied, $\mathrm{T}_{1}$-diagnostics ${ }^{103-105}$ and the largest $\mathrm{T}_{1}$ and $\mathrm{T}_{2}$ amplitudes from converged CCSD wave functions are compiled in the Supporting Information (Table S19). From these we see that all $\mathrm{T}_{1}$ diagnostics are below the standard multireference thresholds of 0.02 and 0.04 for closed and open shell species, respectively, with several notable exceptions. The neutral cyclic $\mathrm{C}_{6}-\mathrm{C}_{10}$ species all exhibit $\mathrm{T}_{1}$ diagnostics above these thresholds, with values as large as 0.056 for cyclic $\mathrm{C}_{9}$. The value for cyclic $\mathrm{C}_{8}{ }^{+}$is similarly large (0.053), arising primarily from a single large $T_{1}$ amplitude of 0.33 . While for these selected carbon clusters the $T_{1}$ diagnostic is outside of the 'safe' range, we can readily justify the use of single reference $\operatorname{CCSD}(\mathrm{T})$ in the present work. First, the largest maximum doubles $\left(\mathrm{T}_{2}\right)$ amplitudes in the CCSD wave functions of the clusters (Table S19) occur for cyclic $\mathrm{C}_{5}(0.21)$ and linear $\mathrm{C}_{5}{ }^{+}(0.19)$, and no other values exceed 0.15 . Second, there are consistently small differences between the complete basis set limit CCSD and CCSD(T) predicted IPs. Based on the focal point tables (see Supporting Information), the predicted IPs appear to be converged to within $0.1 \mathrm{eV}$ or better with respect to the inclusion of electron correlation for all clusters except linear $\mathrm{C}_{5}$, despite the large $\mathrm{T}_{1}$ diagnostic values in some cases. Apparently, any deficiencies in the single-reference coupled 
cluster results for these systems are largely canceling in the determination of IPs. Such cancellation is not apparent in the computed relative energies, and these consequently contain a higher degree of uncertainty. Details of the relative energies of the cyclic and linear isomers will be the subject of future work.

The distortion of the cyclic clusters from regular polygons to lower symmetry has been investigated previously. ${ }^{35,37,42 \mathrm{~d}, 46 \mathrm{~d}, 53 \mathrm{~b}}$ Martin and Taylor ${ }^{42 \mathrm{~d}}$ concluded that the global minimum cyclic $\mathrm{C}_{10}$ geometry is of $\mathrm{D}_{5 \mathrm{~h}}$ symmetry, with a barrier to pseudorotation (through the $\mathrm{D}_{10 \mathrm{~h}^{-}}$ symmetric stationary point) of $1.0 \pm 0.1 \mathrm{kcal} / \mathrm{mol}(4.2 \mathrm{~kJ} / \mathrm{mol})$. Similarly, cyclic $\mathrm{C}_{6}$ and $\mathrm{C}_{8}$ have been shown to possess lower symmetry $\left(\mathrm{D}_{3 \mathrm{~h}}\right.$ and $\mathrm{C}_{4 \mathrm{~h}}$, respectively) than that which would arise from a regular polygonal arrangement. ${ }^{35,37,46 \mathrm{~d}, 53 \mathrm{~b}}$ All of the structures in the present work are consistent with the most reliable results in the literature.

The issue of electronic symmetry breaking in neutral and cationic linear carbon clusters has also been addressed in the literature..$^{38,53,56,57}$ For the neutral linear systems, Liang and Schaefer ${ }^{38}$ discussed symmetry breaking in the ${ }^{1} \Delta_{\mathrm{g}}$ states for $\mathrm{C}_{4}, \mathrm{C}_{6}, \mathrm{C}_{8}$, and $\mathrm{C}_{10}$, attributing the phenomenon to Hartree-Fock theory favoring acetylenic structures over the corresponding cumulenic forms (which are favored by correlated methods). The ground electronic ${ }^{3} \Sigma_{\mathrm{g}}{ }^{-}$states for these systems are not subject to symmetry breaking. In general, for the cationic linear clusters, the ${ }^{2} \Sigma_{\mathrm{u}}{ }^{+}$electronic states are expected to be susceptible to symmetry breaking, because the predominant Lewis structures localize charge in s orbitals at the ends of the chains. In the competing ${ }^{2} \Pi$ states, the unpaired electron resides in a delocalized $\mathrm{p}$ orbital, and symmetry breaking difficulties are averted. Of the linear cationic clusters studied here, only $\mathrm{C}_{5}^{+}{ }^{+}$possesses a ${ }^{2} \Sigma_{\mathrm{u}}^{+}$ground electronic state. The low-lying states of this system have been examined in detail by Schnell, Mühlhäuser, Froudakis, and Peyerimhoff, ${ }^{53}$ who concluded based on multireference configuration interaction (MRD-CI) and $\operatorname{CCSD}(\mathrm{T})$ computations that the ground state global minimum maintains $\mathrm{D}_{\infty \mathrm{h}}$ symmetry. Similar discussions of symmetry breaking in linear carbon clusters within DFT computations have been presented by Orlova et al. ${ }^{57}$ and Díaz-Tendero et 
al. ${ }^{56}$ All of the structures presented here should correspond to physical minima and not the result of artifactual lowering of symmetry due to instabilities in the Hartree-Fock orbitals.

Except for $\mathrm{C}_{6}$ and $\mathrm{C}_{10}$, the cyclic isomers for each cluster are predicted to have lower adiabatic ionization potentials than the corresponding linear isomers. The adiabatic and vertical IP values are essentially the same for all of the linear isomers, whereas the cyclic isomers exhibit some small differences between these two values. In nearly every case the difference in IP between the linear and cyclic structures is large enough so that our experiment should be able to distinguish these. A more complete description of these results is provided in the Supporting Information for this paper. The discussion below compares our theoretical and experimental results for each cluster size, and compares the new results to previous work.

\section{$\mathrm{C}_{4}$}

Previous theoretical work on both neutral and cationic forms of $\mathrm{C}_{4}$ have identified linear and cyclic (rhombus) structures that lie close in energy. The linear neutral species has been characterized spectroscopically, ${ }^{5,7-9,62}$ but the neutral rhombic structure has not been detected experimentally. Ion mobility measurements indicate a single isomer for the cation, which was assigned to the linear species. ${ }^{79}$ The anion prefers the linear structure, and it photodetaches to produce the linear neutral, providing data on excited states of this species. ${ }^{76}$ Our computations find the cyclic form $\left({ }^{1} \mathrm{~A}_{\mathrm{g}}\right)$ to lie slightly lower in energy $(1.1 \mathrm{kcal} / \mathrm{mol} ; 4.6 \mathrm{~kJ} / \mathrm{mol})$ than the linear $\left({ }^{3} \Sigma_{\mathrm{g}}{ }^{-}\right)$form for the neutral. The same pattern is found for the cation, although the energy difference is somewhat greater $(3.4 \mathrm{kcal} / \mathrm{mol} ; 14.2 \mathrm{~kJ} / \mathrm{mol})$. The ionization potentials for these two species are quite close, with the adiabatic and vertical values calculated for the cyclic species $\left(\mathrm{IP}_{\mathrm{a}} / \mathrm{IP}_{\mathrm{v}}=10.9 / 11.3 \mathrm{eV}\right)$ encompassing these two values for the linear species $(11.0 / 11.1 \mathrm{eV})$.

Because the linear and cyclic isomers are so close in energy for this system, we have investigated the effect of entropy on this system to determine the likely isomers present under actual experimental conditions. Using vibrational frequencies from previous theory, ${ }^{34}$ we have calculated the free energy versus temperature for the linear and cyclic isomers of $\mathrm{C}_{4}$ (see Supporting Information). We find that the free energies for these are roughly the same at a 
temperature of about $500 \mathrm{~K}$. Because of the hot plasma growth conditions and the high condensation energy of carbon, together with the incomplete quenching from the helium expansion gas, the temperature of our clusters could easily be in this range, or even higher. Therefore, we expect both linear and cyclic isomers of $\mathrm{C}_{4}$ to be present in our experiment. As shown in Figure 3, the experimental ionization threshold for $\mathrm{C}_{4}$ occurs at $10.35 \mathrm{eV}$, which is well below the value predicted by theory for either of the cyclic or linear isomeric structures. This discrepancy is surprising, because theory should be highly accurate for such a small cluster system. Because we calculate a non-trivial difference between the adiabatic and vertical IP values, we expect an experimental value to lie somewhere between these in the 10.9$11.3 \mathrm{eV}$ range, but the actual value lies almost a volt below this. This difference is too much to attribute to hot vibrational or rotational structure. Therefore, we consider the possible presence of excited electronic states. The energetic positions of excited electronic states for linear $\mathrm{C}_{4}$ have been documented in the photoelectron spectroscopy of the anions by Neumark and coworkers. ${ }^{76}$ Relative to the ${ }^{3} \Sigma_{\mathrm{g}}{ }^{-}$ground state, excited ${ }^{1} \Delta_{\mathrm{g}},{ }^{1} \Sigma_{\mathrm{g}}{ }^{+},{ }^{3} \Pi_{\mathrm{g}},{ }^{3} \Pi_{\mathrm{u}},{ }^{1} \Pi_{\mathrm{u}}$ and ${ }^{1} \Pi_{\mathrm{g}}$ states were assigned to lie at $0.33,0.93,0.82,0.93,1.16$ and $1.41 \mathrm{eV}$. Of these, the ${ }^{1} \Delta_{\mathrm{g}}$ and ${ }^{1} \Sigma_{\mathrm{g}}{ }^{+}$states would be metastable with respect to emission to the ground state and would lie in about the right energy range to explain our data. Similar data for excited states of the cyclic $\mathrm{C}_{4}$ neutral are available from theory. ${ }^{1}$ Relative to the ${ }^{1} \mathrm{~A}_{\mathrm{g}}$ ground state, there is a triplet state lying about $0.9 \mathrm{eV}$ above the ground state. Therefore, low-lying metastable excited states are expected for both linear and cyclic $\mathrm{C}_{4}$, and it seems that the presence of some of these states could explain the lower ionization potential for $\mathrm{C}_{4}$. Because of the likely presence of excited states, and the close IP values predicted for linear and cyclic species, we can make no conclusion about the presence of or the propensity for forming either of these two isomers.

The experimental IP of $\mathrm{C}_{4}$ measured here is also significantly lower than the previous one measured by charge transfer bracketing $(12.54 \mathrm{eV}){ }^{31}$ Considering that there may be excited electronic states present in our system, our experimental values do not provide a definitive comparison to this data. However, all available theory predicts an IP for $\mathrm{C}_{4}$ near $10-11 \mathrm{eV}$. It 
therefore seems that the CTB experiment was problematic for this cluster. An additional experimental value for this IP has been reported by Benedikt et al. ${ }^{100}$ using electron impact ionization of species produced in an acetylene plasma. Their value of $11.9 \pm 0.5 \mathrm{eV}$ is higher than our TPI value, but more in line with our theoretical predictions.

In very recent theoretical work, Hochlaf et al. ${ }^{106}$ have examined the ground and excited electronic states of several isomers of $\mathrm{C}_{4}$ and $\mathrm{C}_{4}{ }^{+}$, to aid in the interpretation of the measured photoionization efficiency curve for $\mathrm{C}_{4}$. Based on CASSCF and MRCI computations, this group suggests that the observed PIE spectrum arises from multiple accessible ionization channels involving several isomers and electronic states of $\mathrm{C}_{4}$ and $\mathrm{C}_{4}{ }^{+}$. This analysis is consistent with our findings that the presence of excited states of $\mathrm{C}_{4}$ in the molecular beam leads to a lowering of the observed ionization threshold compared to the theoretically predicted value.

\section{$\mathrm{C}_{5}$}

Previous computations have found that a linear structure is highly favored for both neutral and cationic $\mathrm{C}_{5}$, and our results confirm this. The linear $\mathrm{C}_{5}$ neutral in its ${ }^{1} \Sigma_{\mathrm{g}}{ }^{+}$ground state has been detected with multiple spectroscopic methods, ${ }^{1,5,7-9,62}$ and the $\mathrm{C}_{5}{ }^{+}$cation has been assigned to be linear in ion mobility experiments. ${ }^{79}$ Because of the strong energetic preference for the linear structure, and the fact that entropy also favors this structure, it seems likely that only the linear species should be present in the experiment. Theory predicts that the linear isomer should have a somewhat higher IP $\left(\operatorname{IP}_{\mathrm{a}} / \mathrm{IP}_{\mathrm{v}}=11.4 / 11.4 \mathrm{eV}\right)$ than the cyclic one $\left(\mathrm{IP}_{\mathrm{a}} / \mathrm{IP}_{\mathrm{v}}=\right.$ $10.4 / 10.8 \mathrm{eV}$ ), with only the cyclic system having a discernible difference between the adiabatic and vertical values. Our measured threshold spectrum is shown in Figure 4. Again, the experimental IP $(9.9 \mathrm{eV})$ is lower than the values computed for either structure, and it is much lower $(1.5 \mathrm{eV})$ than the value for the expected linear structure. It would seem that this system also has excited electronic states populated. Although the photoelectron spectroscopy of the corresponding anion finds no evidence for any excited states at low energies, ${ }^{76}$ calculations by Giuffreda et al. ${ }^{47}$ found the lowest triplet states near 1.2-1.3 eV. Therefore, even though these do not show up in the photoelectron spectra, it seems that there may be low-lying triplet states 
present, and metastable population in these states could explain our low IP. One feature of our threshold spectrum is consistent with this. There is a shelf of weak ionization intensity extending from the onset at 9.6 up to about $10.5 \mathrm{eV}$. Above this point, which corresponds to the predicted threshold for the cyclic species, the intensity rises sharply. This could be indicating a small population of excited states giving ionization below $10.5 \mathrm{eV}$ and a larger population of ground state species causing the ionization above this.

As we saw for $\mathrm{C}_{4}$, the IP measured by charge transfer bracketing $(12.26 \mathrm{eV})^{31}$ is much higher than our experimental value and also higher than any of the theoretical values for this system. Again, there seems to be some problem with the CTB method for this system. However, an electron impact ionization value of $11.4 \pm 0.5 \mathrm{eV}$ was also reported by Benedikt et al., ${ }^{100}$ and this is in good agreement with our calculated value for the more stable linear species.

\section{$\mathbf{C}_{6}$}

Like $\mathrm{C}_{4}$, the $\mathrm{C}_{6}$ cluster has provoked much discussion and many investigations about isomeric structures. ${ }^{1,5,7}$ Although linear structures were favored in early studies, more recent work has established the cyclic $\mathrm{D}_{3 \mathrm{~h}}$ species as the most stable structure. ${ }^{7}$ In our calculations this is also the case, with the cyclic ${ }^{1} \mathrm{~A}_{1}{ }^{\prime}$ ground state predicted to lie $15.3 \mathrm{kcal} / \mathrm{mol}(64.0 \mathrm{~kJ} / \mathrm{mol})$ below the lowest linear ${ }^{3} \Sigma_{\mathrm{g}}{ }^{-}$state. A similar pattern is found for the cation, with a $\mathrm{C}_{2 \mathrm{v}}$ ground ${ }^{2} \mathrm{~A}_{1}$ state lying $8.5 \mathrm{kcal} / \mathrm{mol}(35.6 \mathrm{~kJ} / \mathrm{mol})$ below the ${ }^{2} \Pi$ state. Spectroscopic studies have characterized both the linear and cyclic isomers of the neutral, ${ }^{1,5,7,69}$ and Maier and coworkers ${ }^{78}$ have recently presented matrix isolation spectra for both isomers of the cation. Ion mobility measurements on the cation found a single peak assigned to the linear structure. ${ }^{79}$

Because experimental studies have found evidence for both the linear and cyclic isomers of the neutral, we have also investigated the free energy for these two species (see Supporting Information). Using the method described above for $\mathrm{C}_{4}$, we find that the free energy versus temperature curves for these two isomers cross at about $1100 \mathrm{~K}$. Again, although this is a relatively high temperature for clusters produced in supersonic beams, the condensation energy 
of carbon, which heats the clusters, is quite high and a temperature close to this cannot be ruled out in this experiment. Therefore, it is conceivable that both isomeric species are present.

The threshold spectrum for $\mathrm{C}_{6}$ is shown in Figure 5. The ionization potential that we measure is $9.45 \mathrm{eV}$, compared to our computed values of $\mathrm{IP}_{\mathrm{a}} / \mathrm{IP}_{\mathrm{v}}=9.9 / 10.0$ and $10.2 / 10.6 \mathrm{eV}$, respectively, for the linear and cyclic isomers. Again we find a threshold that is lower than the value predicted for either isomer, although the discrepancy here is not so large as it was for $\mathrm{C}_{4}$ and $\mathrm{C}_{5}$. As described for $\mathrm{C}_{4}$ and $\mathrm{C}_{5}$, we must consider the possible presence of metastable excited states. Linear $\mathrm{C}_{6}$ has a pattern of states similar to that for $\mathrm{C}_{4}$. The ground state is ${ }^{3} \Sigma_{\mathrm{g}}{ }^{-}$, and a ${ }^{1} \Delta_{\mathrm{g}}$ excited state, which would be metastable, was measured by photoelectron spectroscopy at an energy of $0.166 \mathrm{eV} .^{76}$ Other excited electronic states have been calculated at energies close to this. ${ }^{1}$ Therefore, it seems that the presence of unquenched excited states is possible, and this may also contribute to the IP lowering for $\mathrm{C}_{6}$.

The charge transfer bracketing experiments found an IP for $\mathrm{C}_{6}$ of $9.7 \pm 0.2 \mathrm{eV}^{31}$ This is somewhat higher than our value of $9.45 \mathrm{eV}$, and is only a little lower than the value predicted here for the linear isomer (9.9-10.0 eV). The ion mobility data found evidence only for the linear isomer of the cation, ${ }^{79}$ and this would have been the species studied in the CTB experiment. Interestingly, the ionization potentials from the CTB data were much higher than our thresholds for the smaller clusters, but beginning at $n=6$ those values are comparable to, or even lower than, our values.

$\mathrm{C}_{7}$

$\mathrm{C}_{7}$ is perhaps one of the most interesting small carbon clusters because it begins a trend in which the most stable structures are different for the neutral and the cation. The neutral is generally agreed to be more stable in the linear cumulene configuration, analogous to $\mathrm{C}_{5}$, whereas the cation is more stable in a cyclic $\mathrm{C}_{2 \mathrm{v}}$ structure. The linear neutral species has been studied with spectroscopy in both rare gas matrices and in the gas phase. ${ }^{1,5,7}$ Bowers and coworkers ${ }^{79}$ studied the ion mobility of $\mathrm{C}_{7}{ }^{+}$, finding both the linear and cyclic forms in roughly equal abundance. Consistent with earlier theoretical studies, we find that the linear neutral 
species in its ${ }^{1} \Sigma_{\mathrm{g}}{ }^{+}$ground state lies $9.6 \mathrm{kcal} / \mathrm{mol}(40.2 \mathrm{~kJ} / \mathrm{mol})$ lower than the best cyclic structure, which has $\mathrm{C}_{2 \mathrm{v}}$ symmetry. Likewise, our data is in agreement that the cyclic $\mathrm{C}_{2 \mathrm{v}}$ species in its ${ }^{2} \mathrm{~B}_{2}$ ground state is much more stable $(35.4 \mathrm{kcal} / \mathrm{mol}, 148.1 \mathrm{~kJ} / \mathrm{mol})$ for the cation than the linear species. As we noted for $\mathrm{C}_{5}$, because the linear species is more stable and it is favored by entropy, we expect this species to be prominent for neutral clusters in our experiment.

The ionization spectrum for $\mathrm{C}_{7}$ shown in Figure 6 provides a threshold of $10.1 \mathrm{eV}$. Compared to this, the IPs calculated are 8.4/9.1 eV for the cyclic species and 10.4/10.4 eV for the linear species. For the first time, we find an experimental value that is significantly higher than that predicted for one isomer, and only slightly below the threshold predicted for the other isomer. We have accounted for the issue of vertical versus adiabatic thresholds with our calculations, and other factors (e.g., unquenched excited states) could only make the IP lower than expected. Therefore, this data supports the presence of primarily the linear neutral species.

Interestingly, the ionization potential determined by charge transfer bracketing $(8.09 \mathrm{eV})$ is much lower here than our threshold value. ${ }^{31}$ However, in this case this difference is completely understandable. Our experiment begins with neutral clusters, where a linear structure is expected, and we find an IP consistent with that. However, the CTB experiment begins with selected cations. Because the cation is highly favored in the cyclic structure, the CTB experiment would derive the IP for that isomer. Indeed, the IP derived is quite close to the adiabatic prediction $(8.4 \mathrm{eV})$ for the cyclic species.

$\mathrm{C}_{8}$

Like the other even-numbered carbon clusters, $\mathrm{C}_{8}$ has been suggested by theory to adopt both linear and cyclic structures. The cyclic $\mathrm{C}_{4 \mathrm{~h}}\left({ }^{1} \mathrm{~A}_{\mathrm{g}}\right)$ species is generally regarded to be more stable than the linear ${ }^{3} \Sigma_{\mathrm{g}}{ }^{-}$species. Matrix isolation spectroscopy has found spectra assignable to both isomeric forms, ${ }^{1,5,7,67-69}$ while gas phase electronic spectroscopy has detected the linear species. ${ }^{62}$ Photoelectron spectroscopy of the linear anion has probed the linear ground state. ${ }^{76}$ Ion mobility experiments on the cation found both isomers, and annealing experiments established that the cyclic species was more stable. ${ }^{79}$ 
Our focal point extrapolations find relative energies consistent with the earlier predictions, indicating that the cyclic neutral lies $10.6 \mathrm{kcal} / \mathrm{mol}(44.4 \mathrm{~kJ} / \mathrm{mol})$ below the linear species. Likewise, the cyclic cation in its ${ }^{2} \mathrm{~A}_{\mathrm{u}}$ ground state is found to be $20.4 \mathrm{kcal} / \mathrm{mol}(85.4$ $\mathrm{kJ} / \mathrm{mol}$ ) more stable than the ${ }^{2} \Pi$ linear isomer. The IPs calculated are 8.8/9.0 eV for the cyclic species and 9.2/9.3 eV for the linear species. The experimental threshold (not shown here; see Supporting Information) rises gradually from the noise with an onset at $9.15 \mathrm{eV}$. This is only slightly higher than the predicted value for the cyclic species, but it is also only slightly lower than the value for the linear system. Considering the small signal size relative to other clusters (see Figures 1 and 2), and the close values for the IPs predicted, it seems that no firm conclusions can be made here about the likely abundance of isomers present. For comparison, the charge transfer bracketing experiment obtained an IP of $8.76 \mathrm{eV}$, which is lower than our experimental value, but close to our theoretical value for the cyclic species. ${ }^{31}$

\section{$\mathrm{C}_{9}$}

Like the other odd-numbered carbon clusters, $\mathrm{C}_{9}$ is generally regarded to be most stable in its linear ${ }^{1} \Sigma_{\mathrm{g}}^{+}$ground state. However, a cyclic structure lies close to this in energy, with the spacing very sensitive to the level of theory employed (see Supporting Information, Table S15). Like $\mathrm{C}_{7}^{+}$, the ground state $\mathrm{C}_{9}^{+}$cation is much more favorable in a cyclic structure. Both gas phase spectroscopy and matrix isolation infrared measurements have documented the structure of the linear neutral. ${ }^{1,5,7-9,62}$ The anion is also believed to be linear and has been studied with photoelectron spectroscopy. ${ }^{76}$ The cation has been investigated with ion mobility measurements, ${ }^{79}$ which found evidence for both the linear and cyclic isomers. However, annealing experiments established the cyclic species to be more stable.

Our computations also find that the linear structure lies slightly lower than the cyclic species for the neutral. However, as shown in Table 2, the energetics gradually begins to favor the cyclic species for the odd-numbered clusters as size increases. At $\mathrm{C}_{9}$, the energy difference is only $3.4 \mathrm{kcal} / \mathrm{mol}(14.2 \mathrm{~kJ} / \mathrm{mol})$. The cation species is much more stable in its cyclic $\mathrm{C}_{2 \mathrm{v}}\left({ }^{2} \mathrm{~B}_{1}\right)$ ground state, lying $25.7 \mathrm{kcal} / \mathrm{mol}(107.5 \mathrm{~kJ} / \mathrm{mol})$ lower than the linear structure. The IPs 
computed here are 9.6/9.6 eV for the linear species and 8.4/8.8 eV for the cyclic species. The experimental threshold is shown in Figure 7, which exhibits an onset at $9.4 \mathrm{eV}$. This is well above the prediction for the cyclic species and only slightly lower than the value predicted for the linear isomer. Apparently, only the linear species is present in our experiment. A preference for the linear species is understandable because it is lower in energy and it is favored by entropy. The charge transfer bracketing experiments derived a much lower IP for $\mathrm{C}_{9}$ of $8.76 \mathrm{eV} .^{31} \mathrm{As}$ shown, this is closer to the value predicted by theory for the cyclic species. Analogous to $\mathrm{C}_{7}^{+}$, this is understandable because the CTB experiment begins with a selected cation, whose structure for $\mathrm{C}_{9}^{+}$is indeed expected to be cyclic.

\section{$\mathrm{C}_{10}$}

$\mathrm{C}_{10}$ is well known to represent a structural transition point for small neutral carbon clusters. $^{1,5}$ Although linear structures are calculated to be either lower or comparable in energy to cyclic species for all smaller clusters, at $\mathrm{C}_{10}$ and beyond, cyclic species are predicted to be much more stable. ${ }^{1,5,7} \mathrm{C}_{10}$ also satisfies Hückel's Rule for aromaticity, and it is thought that this gives it added stability. ${ }^{5}$ The cation is also strongly favored by theory in its cyclic configuration. ${ }^{1,5,7}$ Matrix isolation and gas phase IR spectroscopy have described the linear species, ${ }^{1,5,7-9,64}$ while an electronic transition in a neon matrix has been assigned to the cyclic species. ${ }^{69}$ The cation was shown convincingly by ion mobility measurements to have the predicted cyclic structure. $^{79}$

Our computations also find that the cyclic species are much more stable (by over 50 $\mathrm{kcal} / \mathrm{mol}$ ) than the linear ones for both the neutral and the cation, consistent with previous work. The cyclic $\mathrm{C}_{10}$ species adopts a $\mathrm{D}_{5 \mathrm{~h}}$ structure with a closed-shell ground state. For the corresponding $\mathrm{C}_{10}{ }^{+}$cation, we find ${ }^{2} \mathrm{E}_{2}{ }^{\prime}$ ground electronic state in $\mathrm{D}_{5 \mathrm{~h}}$ symmetry, indicating that the minimum energy conformation should be Jahn-Teller distorted. Tracking this distortion leads to a $\mathrm{D}_{2 \mathrm{~h}}$ structure and $\mathrm{a}^{2} \mathrm{~A}_{\mathrm{g}}$ ground state, as shown in the Supporting Information. Our final computations predict a significant IP difference between the linear and cyclic isomers. The linear isomer has a lower IP at $8.8 / 8.8 \mathrm{eV}$, and the IP for the cyclic species is $9.2 / 9.5 \mathrm{eV}$. The 
experimental threshold ionization spectrum is shown in Figure 8. As shown, the onset here is assigned at $9.2 \mathrm{eV}$, which is higher than the theoretical value for the linear species but right on top of the corresponding value for the cyclic structure. As we have already discussed, a value slightly below the predicted one would be understandable if the clusters have some internal energy. However, our measured threshold is certainly consistent with the presence of the cyclic isomer. The charge transfer bracketing experiment found an IP slightly lower than our value at $9.08 \mathrm{eV}^{31}$

\section{$\mathrm{C}_{11}$ to $\mathrm{C}_{15}$}

The theoretical work on clusters in the larger size range is understandably much less reliable than it is for the smaller clusters. Linear and cyclic structures are both expected, with cyclic species lying at lower energy and gaining in stability with increasing size for both neutrals and cations. However, most experimental work continues to find evidence for linear structures. Matrix isolation infrared, Raman and UV-VIS experiments have been applied to these systems, and there are some examples of gas phase spectra. ${ }^{1,5-9,63,68-70}$ Although most of these experiments find evidence for linear species, there is some recent electronic spectroscopy that finds evidence for cyclic $\mathrm{C}_{12}$ and $\mathrm{C}_{14} \cdot{ }^{69}$ Photoelectron spectroscopy ${ }^{74}$ and resonance enhanced photodetachment spectroscopy ${ }^{72}$ have investigated the anions. Ion mobility measurements on the cations finds evidence for only the cyclic species. ${ }^{79}$

Our threshold spectra for these larger clusters are presented only in the Supporting Information; the numerical values for the IPs are presented in Table 1. We were not able to complete focal point calculations on these larger species, and there are virtually no other high level calculations on the IPs in this size range. However, Guiffreda et al. ${ }^{56}$ did report calculated IPs for $\mathrm{C}_{11}(7.6 \mathrm{eV}$ cyclic; $8.6 \mathrm{eV}$ linear $)$ and $\mathrm{C}_{12}(8.2 \mathrm{eV}$ cyclic; $7.9 \mathrm{eV}$ linear). As shown in Table 3, their values for the other clusters are systematically lower than ours by $0.2-0.5 \mathrm{eV}$. If this trend continues, then we can estimate very approximately what the IP values should be for 
these two species. A value near $8 \mathrm{eV}$ would then be expected for cyclic $\mathrm{C}_{11}$ and a value near 9 $\mathrm{eV}$ would be expected for the linear species. Our measured IP of $9.4 \mathrm{eV}$ then seems to be more consistent with a linear structure. For the $\mathrm{C}_{12}$ system, a similar estimate predicts a value near 8.5 $\mathrm{eV}$ for both the cyclic and linear species, consistent with our measured result of $8.4 \mathrm{eV}$. The charge transfer bracketing experiment found a much lower value of $7.45 \mathrm{eV}$ for the $\mathrm{C}_{11}$ species, ${ }^{31}$ perhaps consistent with a cyclic cation in that study. The CTB value for $\mathrm{C}_{12}$ was $8.5 \mathrm{eV}$, which agrees nicely with our value and with theory.

Guiffreda et al. ${ }^{56}$ also obtained theoretical predictions for the IPs of linear and cyclic $\mathrm{C}_{13}$ (8.4 and $7.7 \mathrm{eV}$, respectively) and cyclic $\mathrm{C}_{14}$ and $\mathrm{C}_{15}$ (8.3 and $7.1 \mathrm{eV}$, respectively). However, we find experimental values for $\mathrm{C}_{13}, \mathrm{C}_{14}$ and $\mathrm{C}_{15}$ of $9.3,8.7$ and $8.9 \mathrm{eV}$. The calculated values don't agree particularly well with the experiment, but again if we shift the Guiffreda predictions upward by $0.2-0.5 \mathrm{eV}$, we could produce approximate agreement for linear $\mathrm{C}_{13}$ and cyclic $\mathrm{C}_{14}$. Our IP values can also be compared to the CTB values of $8.09,8.52$ and $7.2 \mathrm{eV}$. Because theory and the ion mobility measurements found such a strong preference for cyclic cations, it is likely that these were the species present in the CTB experiment. If we accept this, and note that our data for the clusters in the range of 7-10 were in reasonable agreement with those from the CTB experiment (when the same structures seemed to be present), we can make further speculative conclusions. Our values for $\mathrm{C}_{14}$ is quite close to the $\mathrm{CTB}$ value, perhaps indicating that we have a similar cyclic species. By contrast, our values for $\mathrm{C}_{13}$ and $\mathrm{C}_{15}$ are much higher than the $\mathrm{CTB}$ results, perhaps indicating again that we have linear species for these odd numbered clusters in the same way that we seem to have linear $\mathrm{C}_{11}$. 


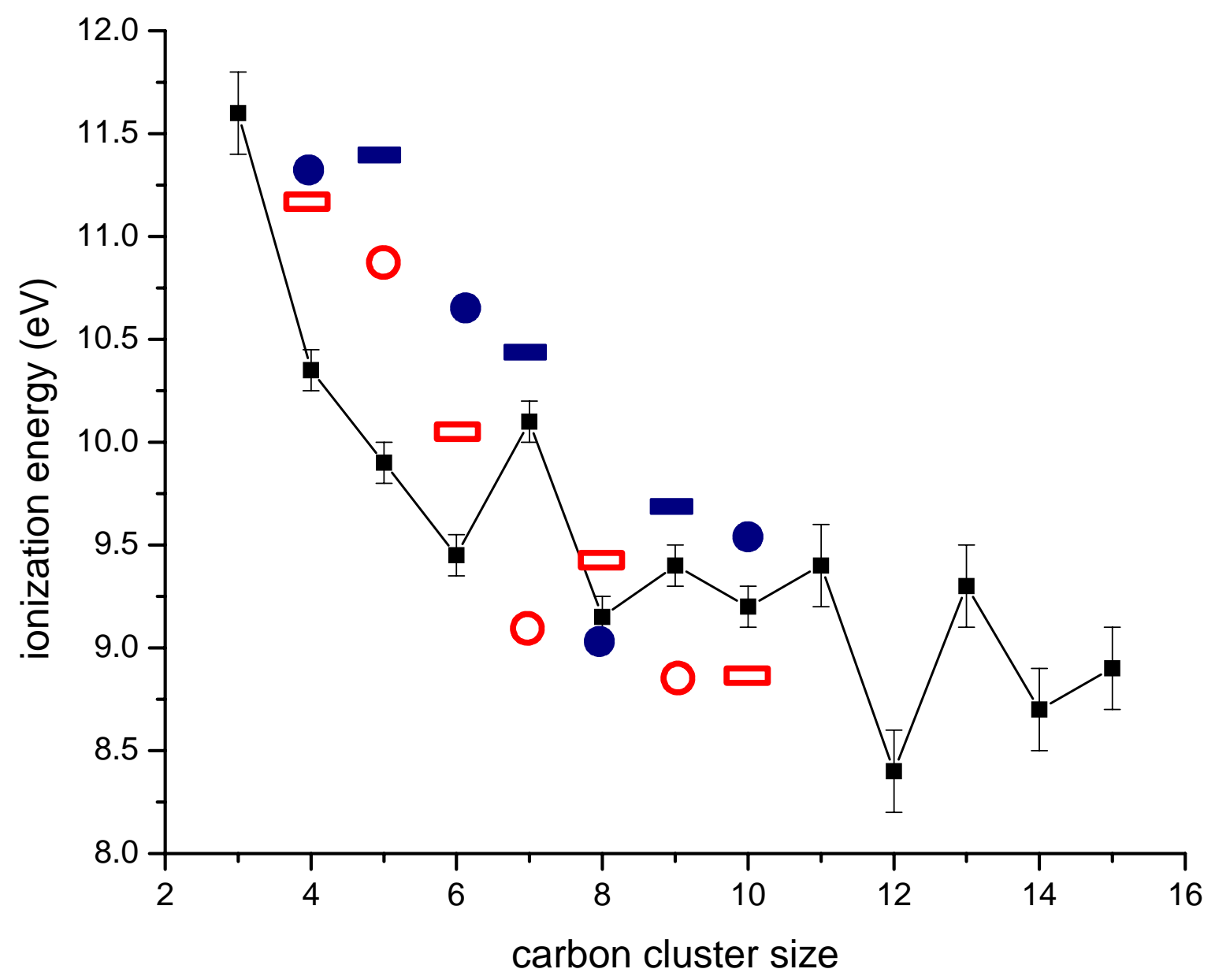

Figure 10. The ionization thresholds measured here for these carbon clusters as a function of size compared to the predictions of theory for different structures. The blue (solid) or red (open) colors of the symbols indicate the vertical IP values for the more or less stable structures, respectively. The circle or rectangle shapes indicate ring or chain species.

Figure 10 shows a graphical summary of all these measured ionization thresholds compared to the predictions of theory. For this comparison, we use the computed vertical IP values. To better visualize the results of theory, we show rectangles to indicate the values for the linear species at each cluster size and circles to indicate the values for the corresponding cyclic species. A blue (solid) symbol indicates the isomer computed to be more stable, whereas a red (open) symbol indicates the less stable isomer. The black square symbols indicate the experimental data. From this figure, it is clear that the experimental data lies well below the predictions of theory for the $n=4-6$ clusters. The $n=7-10$ species lie more in line with theory, and 
as discussed above, their IP values seem to agree with its predictions. As noted above, the best explanation for this behavior is that the smaller clusters have unrelaxed electronic excited states populated, which give them lower effective ionization potentials. Apparently, such unrelaxed excited states are less evident in the larger clusters. Although this behavior might not be predicted, it is understandable. Both of these subgroups of clusters experience many collisions during their growth, but collisional relaxation with helium may not be completely effective in cooling these species. Larger clusters have more condensation energy because they have formed more bonds, and might be expected to be hotter vibrationally than smaller species. However, electronic energy has more influence on ionization potentials than vibrational energy because of the propensity for low $\Delta \mathrm{v}$ transitions. ${ }^{101}$ Electronically excited states could be formed in the growth of either small or large clusters, but apparently these states survive longer in the smaller species. This could be the result of the faster non-radiative rates in the larger clusters. Because their vibrational state densities are greater, processes such as internal conversion and intersystem crossing should be much more effective in relaxing any excited states produced initially. By contrast, the state densities in the small clusters are low enough to limit efficient relaxation, and excited states could survive to influence this experiment. Additionally, excited states present in the larger clusters would lie at lower energies than in the smaller species, thus making these easier to relax collisionally and producing a smaller error in the measured IPs when they are present.

It is evident from Figure 10 that our experimental ionization potentials exhibit an evenodd alternation. Such an alternation has been discussed in the past, ${ }^{1,5,7}$ but it turns out here that the explanation for this behavior is not so simple. The most stable structures for these clusters alternate, with the cyclic isomer lying at lower energy for the even numbered species and linear structures favored for the odd-numbered species. However, no simple trend for IP values applies 
to all linear or all cyclic species. Instead, with the single exception of the $n=8$ cluster, our computations indicate that it is the most stable isomer which has the higher ionization potential. Considering only the linear structures, it has been noted in the past that the ground state should alternate between odd-numbered ${ }^{1} \Sigma_{\mathrm{g}}{ }^{+}$and even-numbered ${ }^{3} \Sigma_{\mathrm{g}}{ }^{-}$species, which should give rise to alternating ionization energies (higher for the singlets). ${ }^{1,5,7}$ Our experiment does not show this, because cyclic structures are likely present for the even species. However, our theoretical IPs do indeed show the expected alternation for the linear species.

\section{Conclusions}

Our theoretical results provide the most reliable data yet available on the structures of these carbon cluster neutrals and ions, as well as their ionization potentials. These data show that the lowest energy structures for the neutrals are linear for the odd-numbered clusters and cyclic for the even-numbered ones. However, as noted before, the energy differences between isomeric structures are not so large in the small clusters. Because entropy favors the linear species, we can expect that both cyclic and linear isomers should be present in most experiments for the even numbered clusters. The odd-numbered clusters are favored energetically and by entropy in linear structures, and so this isomer is expected to dominate most experiments. Our experimental data is inconclusive in the small clusters because of the excited state problem. Likewise, in the larger clusters, the measured ionization potentials for the even-numbered species such as $n=8$ do not provide a clear indication of the structures present, while the $n=10$ data (and perhaps the larger even numbered species) more clearly favor the cyclic species. However, for all of the larger odd-numbered species $(n=7,9,11,13$, etc.), our data support the presence of primarily the linear species.

Our main theoretical focus here was on the ionization potentials of these small carbon clusters rather than on the relative energies of the different isomers. However, a comment about these energetics is in order. Even at the $\operatorname{CCSD}(\mathrm{T})$ and (for the smaller clusters) CCSDT levels, the relative energies reported here are still not converged with respect to electron correlation. 
Although we have recovered most of the error (down to a couple of tenths of a $\mathrm{kcal} / \mathrm{mol}$ ) from basis set incompleteness, it is not possible here to make further improvements regarding the effects of electron correlation for the larger clusters. Therefore, while these energetics are likely better than previous values in the literature, many of them still carry uncertainties of around 3-5 $\mathrm{kcal} / \mathrm{mol}$. On the other hand, the IPs reported here are all well converged (with the exception of linear $\mathrm{C}_{5}$ ) and should be accurate to within $0.2 \mathrm{eV}$.

This is the first experimental study that provides information about the photoionization thresholds of these small carbon clusters. Because these thresholds lie at relatively high energy, only a source like the ALS can generate the required energies and fluxes of tunable VUV needed for these experiments. As shown here, it is possible to combine the ALS light source with pulsed cluster experiments, but these experiments are challenging. Like many other measurements on carbon clusters, issues of cluster temperature and the presence of excited states add complexity to the interpretation of these experiments. However, future refinements in cluster sources will undoubtedly lead to improvements in this experiment, providing new ionization data for these and other atomic cluster systems.

\section{Acknowledgements}

The work at ALS is supported by the Director, Office of Energy Research, Office of Basic Energy Sciences, Chemical Sciences Division of the U.S. Department of Energy under contract no. DE-AC02-05CH11231. Work on this project at the University of Georgia is supported by the Air Force Office of Scientific Research (Duncan Grant No. FA9550-06-1-0028) and the Department of Energy (Schaefer and Allen Grant No. DE-FG02-97ER14748).

\section{Supporting Information}

The Supporting Information for this paper includes the full citation for reference 93, additional threshold ionization spectra, and the full details on the theoretical calculations on the carbon clusters described here. 


\section{References}

(1) Weltner, W. Jr.; Van Zee, R. J. Chem. Rev. 1989, 89, 1713-1747, and references cited therein.

(2) Kroto, H. W.; Allaf, A. W.; Balm, S. P. Chem. Rev. 1991, 91, 1213-1235.

(3) Billups, W. E.; Ciufolini, M. A. Buckminsterfullerenes, VCH Publishers, New York, 1993.

(4) Dresselhaus, M. S.; Dresselhaus, G.; Eklund, P. C. Science of Fullerenes and Carbon Nanotubes, Academic Press, San Diego, 1996.

(5) Van Orden, A.; Saykally, R. J. Chem. Rev. 1998, 98, 2313-2357, and references cited therein.

(6) Lifshitz, C. Int. J. Mass Spectrom. 2000, 200, 423-442.

(7) Weltner, W., Jr.; Van Zee, R. J. J. Molec. Struc. 1990, 222, 201-7.

(8) Maier, J. P. J. Phys. Chem. A 1998, 102, 3462-3469.

(9) Kirkwood, D. A.; Linnartz, H.; Grutter, M.; Dopfer, O.; Motylewski, C. T.; Pachkov, M.; Tulej, M.; Wyss, M.; Maier, J. P. Faraday Disc. 1998, 109, 109-119.

(10) Maier, J. P.; Walker, G. A. H.; Bohlender, D. A. Astrophys. J. 2004, 602, 286-290.

(11) Thaddeus, P.; McCarthy, M. C. Spectrochimica Acta A. 2001, 57A, 757-774.

(12) Hartquist, T. W.; Williams, D. A., eds., The Molecular Astrophysics of Stars and Galaxies, Clarendon Press, Oxford, 1998.

(13) Gardiner, W. C. Combustion Chemistry, Springer-Verlag, New York, 1984.

(14) Strout, D. L.; Scuseria, G. E. J. Phys. Chem. 1996, 100, 6492-6498.

(15) (a) Zheng, G.; Irle, S.; Elstner, M. and Morokuma, K. J. Phys. Chem. A 2004, 108, 31823194. (b) Irle, S.; Zheng, G.; Wang, Z.; Morokuma, K. J. Phys. Chem. B. 2006, 110, 14531-14545.

(16) Rohlfing, E. A.; Cox, D. M.; Kaldor, A. J. Chem. Phys. 1984, 81, 3322-3330.

(17) (a) Kroto, H. W.; Heath, J. R.; O'Brien, S. C.; Curl, R. F.; Smalley, R. E. Nature 1985, 318, 162-163. (b) Curl, R. F.; Smalley, R. E. Science 1988, 242, 1017-1022.

(18) Hahn, M. Y.; Honea, E. C.; Paguia, A. J.; Schriver, K. E.; Camarena, A. M.; Whetten, R. L. Chem. Phys. Lett. 1986, 130, 12-16. 
(19) Rohlfing, E. A. J. Chem. Phys. 1990, 93, 7851-7862.

(20) Moriwaki, T.; Kobayashi, K.; Osaka, M.; Ohara, M.; Shiromaru, H.; Achiba, Y. J. Chem. Phys. 1997, 107, 8927-8932.

(21) Choi, Y.-K.; Im, H.-S.; Jung, K.-W. Int. J. Mass Spectrom. 1999, 189, 115-123.

(22) Bae, C. H.; Park, S. M. J. Chem. Phys. 2002, 117, 5347-5353.

(23) (a) Geusic, M. E.; Jarrold, M. F.; McIlrath, T. J.; Bloomfield, L. A.; Freeman, R. R.; Brown, W. L. Z. Phys. D: Atoms, Molecules and Clusters 1986, 3, 309-17. (b) Geusic, M. E.; McIlrath, T. J.; Jarrold, M. F.; Bloomfield, L. A.; Freeman, R. R.; Brown, W. L. J. Chem. Phys. 1986, 84, 2421-2. (c) Geusic, M. E.; Jarrold, M. F.; McIlrath, T. J.;

Freeman, R. R.; Brown, W. L. J. Chem. Phys. 1987, 86, 3862-9.

(24) O'Brien, S. C.; Heath, J. R.; Curl, R. F.; Smalley, R. E. J. Chem. Phys. 1988, 88, 220-230.

(25) Sowa, M. B.; Hintz, P. A.; Anderson, S. L. J. Chem. Phys. 1991, 95, 4719-10.

(26) Bouyer, R.; Roussel, F.; Monchicourt, P.; Perdix, M.; Pradel, P. J. Chem. Phys. 1994, 100, 8912-19.

(27) (a) Pozniak, B. P.; Dunbar, R. C. Int. J. Mass Spectrom. Ion Processes 1997, 165/166, 299-313. (b) Pozniak, B.; Dunbar, R. C. Int. J. Mass Spectrom. Ion Processes 1994, 133, 97-110.

(28) Radi, P. P.; Bunn, T. L.; Kemper, P. R.; Molchan, M. E.; Bowers, M. T. J. Chem. Phys. 1988, 88, 2809-14.

(29) (a) Gluch, K.; Matt-Leubner, S.; Echt, O.; Concina, B.; Scheier, P.; Mark, T. D. J. Chem. Phys. 2004, 121, 2137-2143. (b) Concina, B.; Gluch, K.; Matt-Leubner, S.; Echt, O.; Scheier, P.; Mark, T. D. Chem. Phys. Lett. 2005, 407, 464-470.

(30) Sowa-Resat, M. B.; Hintz, P. A.; Anderson, S. L. J. Phys. Chem. 1995, 99, 10736-41.

(31) (a) Bach, S. B. H.; Eyler, J. R. J. Chem. Phys. 1990, 92, 358-363. (b) Ramanathan, R.; Zimmerman, J. A.; Eyler, J. R. J. Chem. Phys. 1993, 98, 7838-7845.

(32) Kaizu, K.; Kohno, M.; Suzuki, S.; Shiromaru, H.; Moriwaki, T.; Achiba, Y. J. Chem. Phys. 1997, 106, 9954-9956.

(33) (a) Wakabayashi, T.; Momose, T.; Shida, T. J. Chem. Phys. 1999, 111, 6260-6263. (b) Kato, Y.; Wakabayashi, T.; Momose, T. J. Chem. Phys. 2003, 118, 5390-5394.

(34) (a) Magers, D. H.; Harrison, R. J.; Bartlett, R. J. J. Chem. Phys. 1986, 84, 3284-3290. (b) Watts, J. D.; Gauss, J.; Stanton, J. F.; Bartlett, R. J. J. Chem. Phys. 1992, 97, 8372-8381.

(a) Raghavachari, K.; Whiteside, R. A.; Pople, J. A. J. Chem. Phys. 1986, 85, 6623-6628. 
(b) Raghavachari, K.; Binkley, J. S. J. Chem. Phys. 1987, 87, 2191-2197.

(36) (a) Martin, J. M. L.; François, J-P.; Gijbels, R. J. Chem. Phys. 1989, 90, 3403-3405. (b) Martin, J. M. L.; François, J-P.; Gijbels, R. J. Chem. Phys. 1990, 93, 8850-8861. (c) Martin, J. M. L.; François, J-P.; Gijbels, R. J. Chem. Phys. 1991, 94, 3753-3761. (d) Martin, J. M. L.; François, J-P.; Gijbels, R. J. Chem. Phys. 1991, 95, 9420-9421.

(37) Parasuk, V.; Almlof, J. J. Chem. Phys. 1989, 91, 1137-1141.

(38) a) Liang, C.; Schaefer, H. F. Chem. Phys. Lett. 1990, 169, 150-160. b) Liang, C.; Schaefer, H. F. J. Chem. Phys. 1990, 93, 8844-8849.

(39) Ortiz, J. V.; Zakrzewski, V. G. J. Chem. Phys. 1994, 100, 6614-6619.

(40) Hutter, J.; Luthi, H. P.; Diederich, F. J. Am. Chem. Soc. 1994, 116, 750-756.

(41) Schmatz, S.; Botschwina, P. Chem. Phys. Lett. 1995, 235, 5-12.

(42) (a) Martin, J. M. L.; Taylor, P. R. Chem. Phys. Lett. 1995, 240, 521-525. (b) Martin, J. M. L.; Elyazal, J.; François, J-P. Chem. Phys. Lett. 1995, 242, 570-579. (c) Martin, J. M. L.; Taylor, P. R. J. Chem. Phys. 1995, 102, 8270-8273. (d) Martin, J. M. L.; Taylor, P. R. J. Phys. Chem. 1996, 100, 6047-6056. (e) Martin, J. M. L.; Schwenke, D. W.; Lee, T. J.; Taylor, P. R. J. Chem. Phys. 1996, 104, 4657-4663.

(43) Martin, J. M. L.; El-Yazal, J.; François, J-P. Chem. Phys. Lett. 1996, 252, 9-18.

(44) Ohno, M.; Zakrzewski, V. G.; Ortiz, J. V.; von Niessen, W. J. Chem. Phys. 1997, 106, 3258-3269.

(45) Valdes, E. A.; De La Mora, P.; Castro, M.; Keller, J. Int. J. Quantum Chem. 1997, 65, 867-875.

(46) (a) Hanrath, M.; Peyerimhoff, S. D.; Grein, F. Chem. Phys. 1999, 249, 121-128. (b) Mühlhaüser, M.; Froudakis, G. E.; Hanrath, M.; Peyerimhoff, S. D. Chem. Phys. Lett. 2000, 324, 195-200. (c) Mühlhaüser, M.; Froudakis, G. E.; Peyerimhoff, S. D. Chem. Phys. Lett. 2001, 336, 171-176. (d) Grein, F.; Franz, J.; Hanrath, M.; Peyerimhoff, S. D. Chem. Phys. 2001, 263, 55-60. (e) Mühlhaüser, M.; Froudakis, G. E.; Peyerimhoff, S. D. Phys. Chem. Chem. Phys. 2001, 3, 3913-3916. (f) Hanrath, M.; Peyerimhoff, S. D. Chem. Phys. Lett. 2001, 337, 368-374. (g) Cao, Z. X.; Mühlhaüser, M.; Hanrath, M.; Peyerimhoff, S. D. Chem. Phys. Lett. 2002, 351, 327-334.

(47) Giuffreda, M. G.; Deleuze, M. S.; François, J-P.; Trofimov, A. B. Int. J. Quantum Chem. 2001, 85, 475-491.

(48) Jo, C.; Lee, K. J. Korean Phys. Soc. 2002, 41, 200-204.

(49) Baranovski, V. I. Chem. Phys. Lett. 2005, 408, 429-432. 
(50) Martin, J. M. L.; François, J. P.; Gijbels, R. J. Chem. Phys. 1990, 93, 5037-5045.

(51) Scuseria, G. E. Chem. Phys. Lett. 1991, 176, 27-35.

(52) Watts, J. D.; Stanton, J. F.; Gauss, J.; Bartlett, R. J. J. Chem. Phys. 1991, 94, 4320-4327.

(53) (a) Schnell, M.; Mühlhaüser, M.; Froudakis, G. E.; Peyerimhoff, S. D. Chem. Phys. Lett. 2001, 340, 559-564. (b) Haubrich, J.; Mühlhaüser, M.; Peyerimhoff, S. D. Phys. Chem. Chem. Phys. 2002, 4, 2891-2896. (c) Haubrich, J.; Mühlhaüser, M.; Peyerimhoff, S. D. J. Mol. Spec. 2004, 228, 31-37.

(54) Gillery, C.; Rosmus, P.; Werner, H. J.; Stoll, H.; Maier, J. P. Mol. Phys. 2004, 102, 22272236.

(55) (a) Giuffreda, M. G.; Deleuze, M. S.; François, J.-P. J. Phys. Chem. A 1999, 103, 51375151. (b) Deleuze, M. S.; Giuffreda, M. G.; François, J.-P.; Cederbaum, L. S. J. Chem. Phys. 1999, 111, 5851-5865. (c) Deleuze, M. S.; Giuffreda, M. G.; François, J.-P.; Cederbaum, L. S. J. Chem. Phys. 2000, 112, 5325-5338. (d) Deleuze, M. S.; Giuffreda, M. G.; François, J.-P. J. Phys. Chem. A 2002, 106, 5626-5637.

(56) Díaz-Tendero, S.; Martín, F.; Alcamí, M. J. Phys. Chem. A 2002, 106, 10782-10789.

(57) Orlova, G.; Goddard, J. D. Chem. Phys. Lett. 2002, 363, 486-491.

(58) Schmatz, S.; Botschwina, P. Int. J. Mass Spectrom. Ion Processes 1995, 150, 621-629.

(59) Cao, Z. X.; Peyerimhoff, S. D.; Grein, F.; Zhang, Q. J. Chem. Phys. 2001, 115, 20622068.

(60) Lepine, F.; Allouche, A. R.; Baguenard, B.; Bordas, C.; Aubert-Frecon, M. J. Phys. Chem. A 2002, 106, 7177-7183.

(61) Giuffreda, M. G.; Deleuze, M. S.; François, J-P. J. Phys. Chem. A 2002, 106, 8569-8582.

(62) (a) Motylewski, T.; Vaizert, O.; Giesen, T. F.; Linnartz, H.; Maier, J. P. J. Chem. Phys. 1999, 111, 6161-6163. (b) Linnartz, H.; Vaizert, O.; Motylewski, T.; Maier, J. P. J. Chem. Phys. 2000, 112, 9777-9779. (c) Boguslavskiy, A. E.; Maier, J. P. J. Chem. Phys. 2006, 125, 094308.

(63) Wyss, M.; Grutter, M.; Maier, J. P. Chem. Phys. Lett. 1999, 304, 35-38.

(64) (a) Giesen, T. F.; Berndt, U.; Yamada, K. M. T.; Fuchs, G.; Schieder, R.; Winnewisser, G.; Provencal, R. A.; Keutsch, F. N.; Van Orden, A.; Saykally, R. J. Chem. Phys. Chem. 2001, 2, 242-247. (b) Neubauer-Guenther, P.; Giesen, T. F.; Berndt, U.; Fuchs, G.; Winnewisser, G. Spectrochim. Acta Part A 2003, 59, 431-441.

(65) (a) Cermak, I.; Forderer, M.; Cermakova, I.; Kalhofer, S.; Stopka-Ebeler, H.; Monninger, G.; Kratschmer, W. J. Chem. Phys. 1998, 108, 10129-10142. (b) Monninger, G.; 
Forderer, M.; Gurtler, P.; Kalhofer, S.; Petersen, S.; Nemes, L.; Szalay, P. G.;

Kratschmer, W. J. Phys. Chem. A 2002, 106, 5779-5788.

(66) Lapinski, L.; Vala, M. Chem. Phys. Lett. 1999, 300, 195-201.

(67) Presilla-Marquez, J. D.; Harper, J.; Sheehy, J. A.; Carrick, P. G.; Larson, C. W. Chem. Phys. Lett. 1999, 300, 719-726.

(68) (a) Wang, S. L.; Rittby, C. M. L.; Graham, W. R. M. J. Chem. Phys. 2000, 112, 14571461. (b) Ding, X. D.; Wang, S. L.; Rittby, C. M. L.; Graham, W. R. M. J. Chem. Phys. 2000, 112, 5113-5120.

(69) (a) Grutter, M.; Wyss, M.; Riaplov, E.; Maier, J. P.; Peyerimhoff, S. D.; Hanrath, M. J. Chem. Phys. 1999, 111, 7397-7401. (b) Boguslavskiy, A. E.; Maier, J. P. Phys. Chem. Chem. Phys. 2007, 9, 127-130.

(70) (a) Ott, A. K.; Rechtsteiner, G. A.; Felix, C.; Hampe, O.; Jarrold, M. F.; Van Duyne, R. P.; Raghavachari, K. J. Chem. Phys. 1998, 109, 9652-9655. (b) Rechtsteiner, G. A.; Felix, C.; Ott, A. K.; Hampe, O.; Van Duyne, R. P.; Jarrold, M. F.; Raghavachari, K. J. Phys. Chem. A 2001, 105, 3029-3033.

(71) Tulej, M.; Kirkwood, D. A.; Maccaferri, G.; Dopfer, O.; Maier, J. P. Chem. Phys. 1998, 228, 293-299.

(72) (a) Ohara, M.; Suwa, M.; Ishigaki, T.; Shiromaru, H.; Achiba, Y.; Kratschmer, W. J. Chem. Phys. 1998, 109, 1329-1333. (b) Ohara, M.; Kasuya, D.; Shiromaru, H.; Achiba, Y. J. Phys. Chem. A 2000, 104, 8622-8626.

(73) (a) Lakin, N. M.; Pachkov, M.; Tulej, M.; Maier, J. P.; Chambaud, G.; Rosmus, P. J. Chem. Phys. 2000, 113, 9586-9592. (b) Lakin, N. M.; Guthe, F.; Tulej, M.; Pachkov, M.; Maier, J. P. Faraday Discuss. 2000, 115, 383-393.

(74) Kohno, M.; Suzuki, S.; Shiromaru, H.; Moriwaki, T.; Achiba, Y. Chem. Phys. Lett. 1998, 282, 330-334.

(75) Fromherz, R.; Gantefor, G.; Shvartsburg, A. A. Phys. Rev. Lett. 2002, 89, 083001/1083001/4.

(76) (a) Arnold, D.W.; Bradforth, S.E.; Kitsopoulos, T.N.; Neumark, D.M. J. Chem. Phys. 1991, 95, 8753-8764. (b) Xu, C.; Burton, G.R.; Taylor, T.R.; Neumark, D.M. J. Chem. Phys. 1997, 107, 3428-3436. (c) Fri schkorn, C.; Bragg, A. E.; Davis, A. V.; Wester, R.; Neumark, D. M. J. Chem. Phys. 2001, 115, 11185-11192.

(77) Szczepanski, J.; Hodyss, R.; Vala, M. J. Phys. Chem. A 1998, 102, 8300-8304.

(78) (a) Fulara, J.; Riaplov, E.; Batalov, A.; Shnitko, I.; Maier, J. P. J. Chem. Phys. 2004, 120, 7520-7525. (b) Fulara, J.; Shnitko, I.; Batalov, A.; Maier, J. P. J. Chem. Phys. 2005, 123, 044305/1-044305/6. 
(79) (a) Von Helden, G.; Hsu, M. T.; Kemper, P. R.; Bowers, M. T. J. Chem. Phys. 1991, 95, 3835-7. (b) Von Helden, G.; Hsu, M. T.; Gotts, N.; Bowers, M. T. J. Phys. Chem. 1993, 97, 8182-92. (c) Von Helden, G.; Gotts, N. G.; Bowers, M. T. J. Am. Chem. Soc. 1993, 115, 4363-4. (d) Von Helden, G.; Gotts, N. G.; Bowers, M. T. Chem. Phys. Lett. 1993, 212, 241-6. (e) Von Helden, G.; Palke, W. E.; Bowers, M. T. Chem. Phys. Lett. 1993, 212, 247-52. (f) Gotts, N. G.; Von Helden, G.; Bowers, M. T. Int. J. Mass Spectrom. Ion Processes 1995, 149/150, 217-29.

(80) (a) Hunter, J. M.; Fye, J. L.; Roskamp, E. J.; Jarrold, M. F. J. Phys. Chem. 1994, 98, 1810-1818. (b) Shvartsburg, A. A.; Hudgins, R. R.; Dugourd, P.; Gutierrez, R.; Frauenheim, T.; Jarrold, M. F. Phys. Rev. Lett. 2000, 84, 2421-2424.

(81) De Vries, J.; Steger, H.; Kamke, B.; Menzel, C.; Weisser, B.; Kamke, W.; Hertel, I. V. Chem. Phys. Lett. 1992, 188, 159-162.

(82) Nicolas, C.; Shu, J. N.; Peterka, D. S.; Hochlaf, M.; Poisson, L.; Leone, S. R.; Ahmed, M. J. Am. Chem. Soc. 2006, 128, 220-226.

(83) Metz, R. B.; Christophe Nicolas, C.; Ahmed, M.; Leone, S. R. J. Chem. Phys. 2005, 123, $114313 / 1-114313 / 6$.

(84) (a) Allen, W. D.; East, A. L. L.; Császár, A. G. in Structures and Conformations of NonRigid Molecules, Laane, J.; Dakkouri, M.; van der Vecken, B.; Oberhammer, H., eds. (Kluwer, Dordrecht, 1993), pp. 343. (b) East, A. L. L.; Allen, W. D. J. Chem. Phys. 1993, 99, 4638 - 4650.

(85) (a) Császár, A. G.; Allen, W. D.; Schaefer, H. F. J. Chem. Phys. 1998, 108, 9751-9764.

(b) Gonzales, J. M.; Pak, C.; Cox, R. S.; Allen, W. D.; Tarczay, G.; Császár, A. G. Chem. Eur. J. 2003, 9, 2173-2192. (c) Schuurman, M.; Muir, S.; Allen, W. D.; Schaefer, H. F. J. Chem. Phys. 2004, 120, 11586-11599. (d) Császár, A. G.; Tarczay, G.; Leininger, M. L.; Polyansky, O. L.; Tennyson, J.; Allen, W. D. in Spectroscopy from Space, edited by Demaison, J.; Sarka, K., Kluwer Publishers, Dordrecht, 2001, pp. 317-339.

(86) Heimann, P. A.; Koike, M.; Hsu, C. W.; Blank, D.; Yang, X. M.; Suits, A. G.; Lee, Y. T.; Evans, M.; Ng, C. Y.; Flaim, C.; Padmore, H. A. Rev. Sci. Instrum. 1997, 68, 1945-1951.

(87) Dunning, T. H. J. Chem. Phys. 1989, 90, 1007-1023.

(88) (a) Bartlett, R. J.; Watts, J. D.; Kucharski, S. A.; Noga, J. Chem. Phys. Lett. 1990, 165, 513-522; Bartlett, R. J.; Watts, J. D.; Kucharski, S. A.; Noga, J. Chem. Phys. Lett. 1990, 167, 609-609. (b) Gauss, J.; Lauderdale, W. J.; Stanton, J. F.; Watts, J. D.; Bartlett, R. J. Chem. Phys. Lett. 1991, 182, 207-215.

(89) Raghavachari, K.; Trucks, G. W.; Pople, J. A.; Head-Gordon, M. Chem. Phys. Lett. 1989, 157, 479-483.

(90) Noga, J.; Bartlett, R. J. J. Chem. Phys. 1987, 86, 7041-7050. 
(91) Scuseria, G. E.; Schaefer, H. F. Chem. Phys. Lett. 1988, 152, 382-386.

(92) Watts, J. D.; Bartlett, R. J. J. Chem. Phys. 1990, 93, 6104-6105.

(93) Werner, H.-J. et al., MOLPRO, version 2002.1, 2003, Birmingham, U. K.

(94) Stanton, J. F.; Gauss, J.; Lauderdale, W. J.; Watts, J. D.; Bartlett, R. J., ACES II. The package also contains modified versions of the MOLECULE Gaussian integral program of Almlöf, J.; Taylor, P. R., the ABACUS integral derivative program of Helgaker, T. U.; Jensen, H. J. A.; Jørgensen, P.; Taylor, P. R. and the PROPS property evaluation code of Taylor, P. R.

(95) Feller, D J. Chem. Phys. 1993, 98, 7059-7071.

(96) Helgaker, T.; Klopper, W.; Koch, H.; Noga, J. J. Chem. Phys. 1997, 106, 9639-9646.

(97) Specifically, in Molpro, the RHF/UCCSD and RHF/UCCSD(T) approaches were used for the open-shell species.

(98) NIST Chemistry WebBook, NIST Standard Reference Database Number 69, June 2005. (http://webbook.nist.gov/chemistry/).

(99) Reid, C. J.; Ballantine, J. A.; Andrews, S. R.; Harris, F. M. Chem. Phys. 1995, 190, 113 122. $(11.4+/-0.3 \mathrm{eV})$.

(100) Benedikt, J.; Agarwal, S.; Eijkman, D.; Vandamme, W.; Creatore, M.; van de Sanden, M. C. M. J. Vac. Sci. Tech. A 2005, 23, 1400.

(101) Ruscic, B. Res. Adv. Phys. Chem. 2000, 1, 39-75.

(102) Cizek, J.; Paldus, J. J. Chem. Phys. 1967, 47, 3976-3985. b) Davidson, E. R.; Borden, W. T. J. Phys. Chem. 1983, 87, 4783-4790. c) McLean, A. D.; Lengsfield III, B. H.; Pacansky, J.; Ellinger, Y. J. Chem. Phys. 1985, 83, 3567-3576. d) Allen, W. D.; Horner, D. A.; DeKock, R. L.; Remington, R. B.; Schaefer, III, H. F. Chem. Phys. 1986, 133, 11 45 (1989). e) Crawford, T. D.; Stanton, J. F.; Allen, W. D.; Schaefer, III, H. F. J. Chem. Phys. 1997, 107, 10626-10632.

(103) Jayatilaka, D.; Lee, T. J. J. Chem. Phys. 1993, 98, 9734-9747.

(104) Lee, T. J.; Rice, J. E.; Scuseria, G. E.; Schaefer, H. F. Theo. Chim. Acta 1989, 75, 81-98.

(105) Lee, T. J.; Taylor, P. R. Int. J. Quant. Chem. 1989, S23, 199-207.

(106) Hochlaf, M.; Nicolas, C.; Poisson, L.; Shu, J. J. Chem. Phys., in press. 
Table 1. Photoionization thresholds measured here compared to the predictions of theory for ionization potentials and to previous IP values determined from charge transfer experiments.

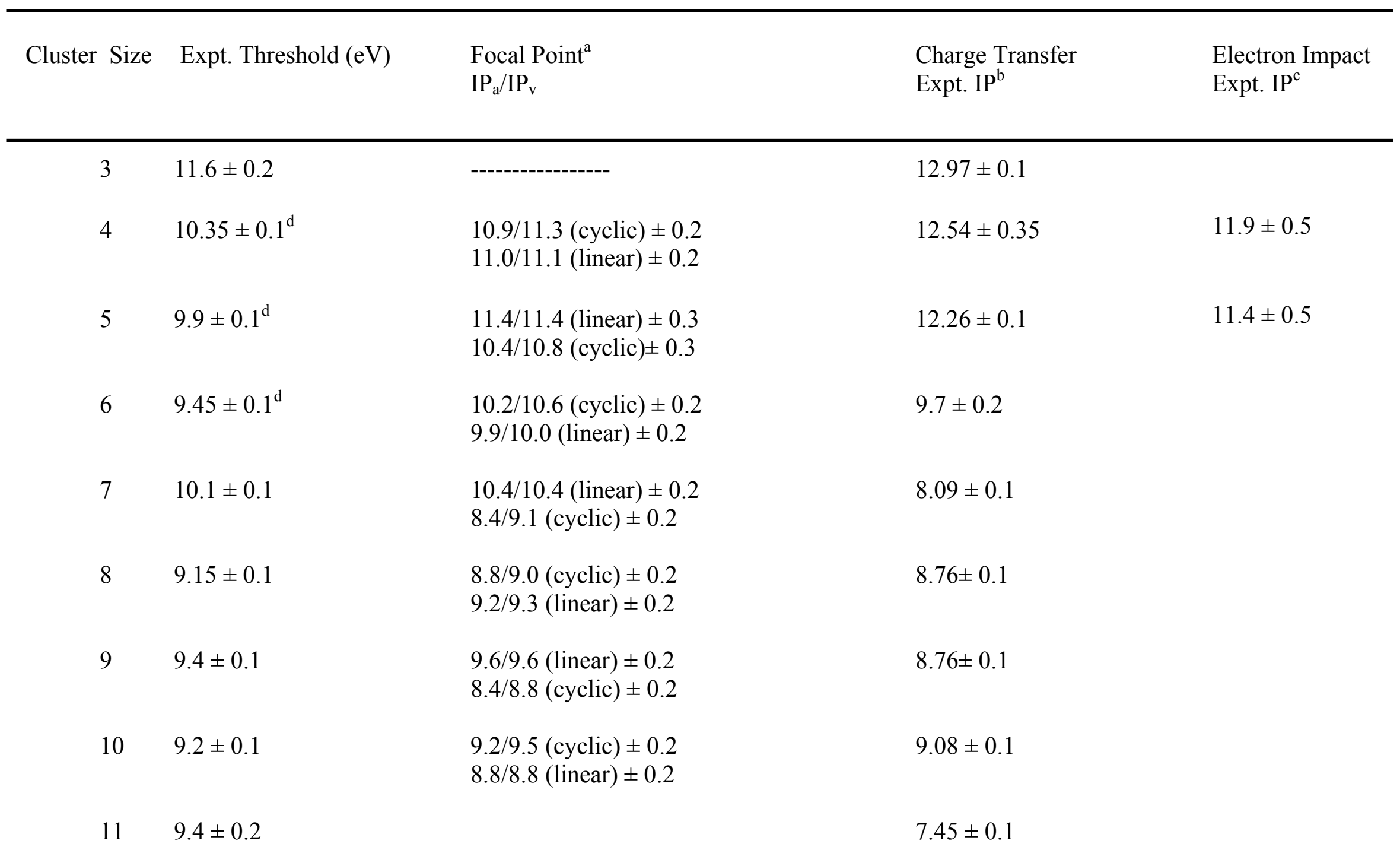


${ }^{a}$ This work. Focal point extrapolated values, computed at cc-pVTZ CCSD(T) optimized geometries, except for $\mathrm{C}_{9}$ and $\mathrm{C}_{10}$, which were computed at cc-pVDZ CCSD(T) optimized geometries.

ref. 31 .

cref. 100.

these threshold values are believed to be lower than the true ionization potentials because of the presence of unquenched excited states. 
Table 2. Point group symmetries, electronic states and relative energies (from focal point extrapolations) of linear $\left(\mathrm{D}_{\infty \mathrm{ch}}\right)$ and cyclic structures for small carbon cluster neutrals and cations.

\begin{tabular}{|c|c|c|}
\hline Cluster size & $\begin{array}{l}\text { symmetry and } \\
\text { electronic state }\end{array}$ & $\begin{array}{l}\text { Relative } \\
\text { energy }(\mathrm{kcal} / \mathrm{mol})\end{array}$ \\
\hline $\mathrm{C}_{4}$ & $\begin{array}{ll}\mathrm{D}_{2 \mathrm{~h}} & { }^{1} \mathrm{~A}_{\mathrm{g}} \\
\mathrm{D}_{\infty \mathrm{h}} & { }^{3} \Sigma_{\mathrm{g}}^{-}\end{array}$ & $\begin{array}{l}0.0 \\
+1.1\end{array}$ \\
\hline $\mathrm{C}_{4}^{+}$ & $\begin{array}{ll}\mathrm{C}_{2 \mathrm{v}} & { }^{2} \mathrm{~B}_{1} \\
\mathrm{D}_{\infty \mathrm{h}} & { }^{2} \Pi\end{array}$ & $\begin{array}{l}0.0 \\
+3.4\end{array}$ \\
\hline $\mathrm{C}_{5}$ & $\begin{array}{ll}\mathrm{C}_{2 \mathrm{v}} & { }^{1} \mathrm{~A}_{1} \\
\mathrm{D}_{\infty \mathrm{h}} & { }^{1} \Sigma_{\mathrm{g}}^{+}\end{array}$ & $\begin{array}{l}+53.5 \\
0.0\end{array}$ \\
\hline $\mathrm{C}_{5}^{+}$ & $\begin{array}{ll}\mathrm{C}_{2 \mathrm{v}} & { }^{2} \mathrm{~A}_{1} \\
\mathrm{D}_{\infty \mathrm{h}} & { }^{2} \Sigma_{\mathrm{u}}^{+}\end{array}$ & $\begin{array}{l}+30.9 \\
0.0\end{array}$ \\
\hline $\mathrm{C}_{6}$ & $\begin{array}{ll}\mathrm{D}_{3 \mathrm{~h}} & { }^{1} \mathrm{~A}_{1^{\prime}} \\
\mathrm{D}_{\infty \mathrm{h}} & { }^{3} \Sigma_{\mathrm{g}}{ }^{-}\end{array}$ & $\begin{array}{l}0.0 \\
+15.3\end{array}$ \\
\hline $\mathrm{C}_{6}^{+}$ & $\begin{array}{ll}\mathrm{C}_{2 \mathrm{v}} & { }^{2} \mathrm{~A}_{1} \\
\mathrm{D}_{\infty \mathrm{h}} & { }^{2} \Pi\end{array}$ & $\begin{array}{l}0.0 \\
+8.5\end{array}$ \\
\hline $\mathrm{C}_{7}$ & $\begin{array}{ll}\mathrm{C}_{2 \mathrm{v}} & { }^{1} \mathrm{~A}_{1} \\
\mathrm{D}_{\infty \mathrm{h}} & { }^{1} \Sigma_{\mathrm{g}}^{+}\end{array}$ & $\begin{array}{l}+9.6 \\
0.0\end{array}$ \\
\hline $\mathrm{C}_{7}^{+}$ & $\begin{array}{ll}\mathrm{C}_{2 \mathrm{v}} & { }^{2} \mathrm{~B}_{2} \\
\mathrm{D}_{\infty \mathrm{h}} & { }^{2} \Pi\end{array}$ & $\begin{array}{l}0.0 \\
+35.4\end{array}$ \\
\hline $\mathrm{C}_{8}$ & $\begin{array}{ll}\mathrm{C}_{4 \mathrm{~h}} & { }^{1} \mathrm{~A}_{\mathrm{g}} \\
\mathrm{D}_{\infty \mathrm{h}} & { }^{3} \Sigma_{\mathrm{g}}\end{array}$ & $\begin{array}{l}0.0 \\
+10.6\end{array}$ \\
\hline $\mathrm{C}_{8}^{+}$ & $\begin{array}{ll}\mathrm{C}_{4 \mathrm{~h}} & { }^{2} \mathrm{~A}_{\mathrm{u}} \\
\mathrm{D}_{\infty \mathrm{h}} & { }^{2} \Pi\end{array}$ & $\begin{array}{l}0.0 \\
+20.4\end{array}$ \\
\hline $\mathrm{C}_{9}$ & $\begin{array}{ll}\mathrm{C}_{2} & { }^{1} \mathrm{~A} \\
\mathrm{D}_{\infty \mathrm{h}} & { }^{1} \Sigma_{\mathrm{g}}^{+}\end{array}$ & $\begin{array}{l}+3.4 \\
0.0\end{array}$ \\
\hline $\mathrm{C}_{9}^{+}$ & $\begin{array}{ll}\mathrm{C}_{2 \mathrm{v}} & { }^{2} \mathrm{~B}_{1} \\
\mathrm{D}_{\infty \mathrm{h}} & { }^{2} \Pi\end{array}$ & $\begin{array}{l}0.0 \\
+25.7\end{array}$ \\
\hline $\mathrm{C}_{10}$ & $\begin{array}{ll}\mathrm{D}_{5 \mathrm{~h}} & { }^{1} \mathrm{~A}_{1^{\prime}} \\
\mathrm{D}_{\infty \mathrm{h}} & { }^{3} \Sigma_{\mathrm{g}}{ }^{-}\end{array}$ & $\begin{array}{l}0.0 \\
+70.6\end{array}$ \\
\hline $\mathrm{C}_{10}{ }^{+}$ & $\begin{array}{ll}\mathrm{D}_{2 \mathrm{~h}} & { }^{2} \mathrm{~A}_{\mathrm{g}} \\
\mathrm{D}_{\infty \mathrm{h}} & { }^{2} \Pi\end{array}$ & $\begin{array}{l}0.0 \\
+60.0\end{array}$ \\
\hline
\end{tabular}


Table 3. Predicted adiabatic ionization potentials $(\mathrm{eV})$ for linear and cyclic carbon clusters.

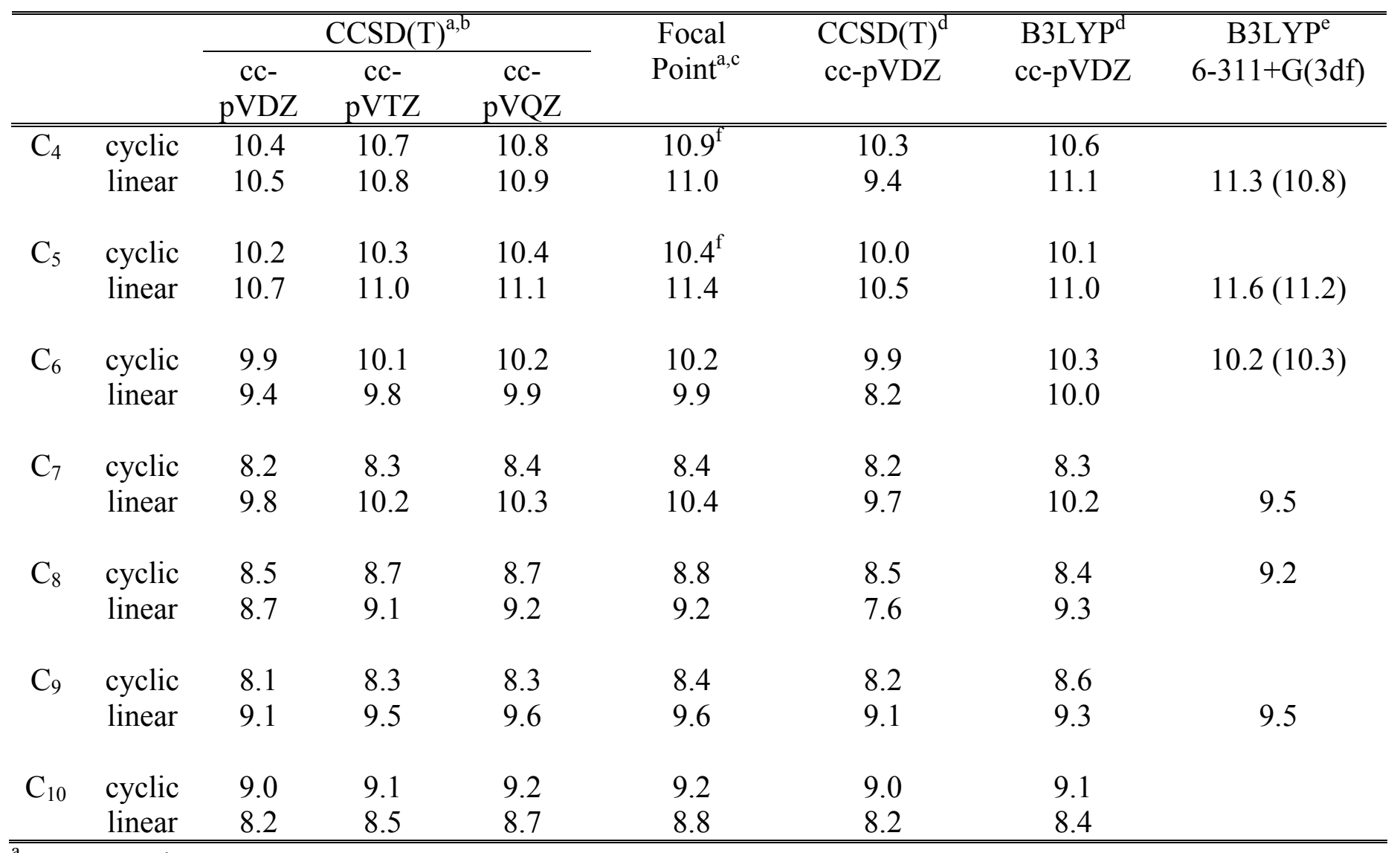

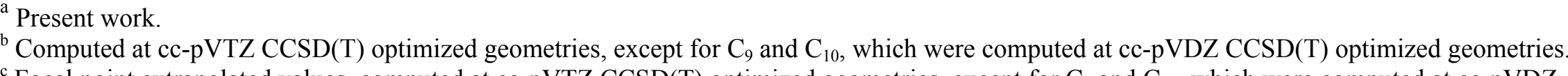
${ }^{\mathrm{c}}$ Focal point extrapolated values, computed at cc-pVTZ $\operatorname{CCSD}(\mathrm{T})$ optimized geometries, except for $\mathrm{C}_{9}$ and $\mathrm{C}_{10}$, which were computed at cc-pVDZ $\operatorname{CCSD}(\mathrm{T})$ optimized geometries. See Supporting Information for detailed valence focal point tables.

${ }^{\mathrm{d}}$ Reference 55a. Computed at cc-pVDZ B3LYP optimized geometries.

${ }^{\mathrm{e}}$ Reference 56. 6-311+G(3df) CCSD(T) results, computed at 6-311+G(3df) B3LYP geometries, are provided in parentheses. This paper does not clearly indicate the isomer for which the IP is determined; we presume that it is the lowest energy one in their work.

${ }_{\mathrm{f}}^{\mathrm{f}}$ Focal point result contains an additional correction from cc-pVDZ CCSDT energies. 
Table of Contents Graphic:

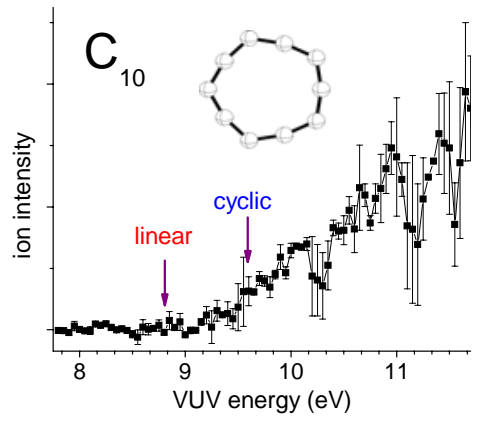

